\title{
Surface engineering to reduce the interfacial resistance for enhanced photocatalytic water oxidation
}

Junqing Yan, ${ }^{a \#}$ Jing Liu, ${ }^{a \#}$ Yujin Ji, ${ }^{b \#}$ Munkhbayar Batmunkh, ${ }^{c}$ Dan Li, ${ }^{a}$ Xiaoshuang Liu, ${ }^{e}$ Xingzhong Cao, ${ }^{e}$ Youyong Li, ${ }^{b *}$ Shengzhong Liu, ${ }^{a *}$ and Tianyi $\mathrm{Ma}^{d *}$

\# These authors contributed equally to this work.

${ }^{a}$ Key Laboratory of Applied Surface and Colloid Chemistry, Ministry of Education, Shaanxi Key Laboratory for Advanced Energy Devices, Shaanxi Engineering Lab for Advanced Energy Technology, School of Materials Science and Engineering, Shaanxi Normal University, Xi'an, 710119, People's Republic of China

E-mail:liusz@snnu.edu.cn

${ }^{b}$ Institute of Functional Nano \& Soft Materials (FUNSOM), Jiangsu Key Laboratory for Carbon-Based Functional Materials \& Devices, Soochow University, Suzhou, Jiangsu 215123, People's Republic of China

E-mail:yyli@suda.edu.cn

${ }^{c}$ Centre for Clean Environment and Energy, Griffith University, Gold Coast, Queensland 4222, Australia

${ }^{d}$ Discipline of Chemistry, School of Environmental and Life Sciences, Faculty of Science, University of Newcastle, Callaghan, NSW 2308, Australia

E-mail: tianyi.ma@newcastle.edu.au

${ }^{e}$ Positron Facility, Institute of High Energy Physics, Chinese Academy of Sciences, Beijing 100049, People's Republic of China 


\begin{abstract}
Interfacial resistance of the charge carriers across $\mathrm{TiO}_{2}$ to co-catalysts is one of the main limiting factors for realizing high photocatalytic efficiency of water oxidation. Herein, an amorphous $\mathrm{TiO}_{\mathrm{x}}$ layer is introduced on the surface of crystalline $\mathrm{TiO}_{2}$ catalyst to form the core-shell structure $\left(\mathrm{am} @ \mathrm{TiO}_{2}\right)$ via a oxidation corrosion method. Owing to the surface disordered Ti-O layer, the obtained am@ $\mathrm{TiO}_{2}$ exposes abundant $-\mathrm{OH}$ groups for the homogeneous loading of nano-sized $\mathrm{IrO}_{\mathrm{x}}$, while the charge carriers interfacial migration is substantially enhanced. The as-prepared $\mathrm{IrO}_{\mathrm{x}}-\mathrm{am} @ \mathrm{TiO}_{2}$ exhibits the photocatalytic water oxidation performance with a $\mathrm{O}_{2}$ evolution rate of $143.6 \mu \mathrm{mol} / \mathrm{g} * \mathrm{~h}$, which is approximately 14 times higher than that of the bare am@ $\mathrm{TiO}_{2}$. Moreover, an apparent quantum yield (AQY) of $18.99 \%$ is obtained under LED-405 illumination. This work provides a direction for improving the photocatalytic performance and helps to gain fundamental understanding on the water oxidation steps.
\end{abstract}

Keywords: $\mathrm{TiO}_{2}$, water oxidation, hole-transfer, photocatalysis, $\mathrm{IrO}_{\mathrm{x}}$, co-catalyst 


\section{Introduction}

Overall water splitting via photocatalysis to hydrogen $\left(\mathrm{H}_{2}\right)$ generation has been considered to be one of the potential technologies for addressing the current energy and greenhouse effect related issues. ${ }^{[1-4]}$ However, its oxidation is the rate-determining step and limits the final efficiency. ${ }^{[5-8]}$ Loading co-catalysts, such as $\mathrm{IrO}_{\mathrm{x}}, \mathrm{RuO}_{\mathrm{x}}$, and $\mathrm{MnO}_{\mathrm{x}}$, onto photocatalysts has been proven to be an effective strategy to improve the water oxidation efficiency, ${ }^{[9-11]}$ but the efficiency is still lower than the theoretical values of the semiconductors. The interface barrier between photocatalyst and co-catalyst is the main cause for reducing the ratio of separated holes reaching the surface. ${ }^{[12]}$

There are three accepted steps for powder semiconductor photocatalysis involved in electron-hole pairs: generation in catalyst under illumination, separation from bulk to surface and reaction at the reduction or oxidation sites. ${ }^{[13-14]}$ It should be noted that not all the separated carriers migrate to the surface reaction sites successfully and the part of carriers consumption reduces the photocatalytic efficiency. ${ }^{[15]}$ That is, how to ensure all the separated electron-hole pairs moving to the surface and participating in the particular reaction is a determinate factor for improving the photocatalytic efficiency. ${ }^{[16]}$ For the loading co-catalyst based photocatalytic water splitting system, one of the available strategies to further improve the solar-to chemical energy efficiency is increasing the ratio of separated carriers taking part in surface reaction, but this has been rarely studied. ${ }^{[17]}$

The most effective strategy for furthest achieving the highest utilization rate of photogenerated carriers is establishing the carrier-transfer channel by using a metal, ${ }^{[18-20]}$ graphene $^{[21-22]}$ or compound materials ${ }^{[23]}$ to form a sandwiched system with photocatalystcarrier transfer-reaction sites. For example, electron-transfer channel based on Au metal was introduced between $\mathrm{TiO}_{2}$ and $\mathrm{CdS}$ to form an anisotropic $\mathrm{CdS}-\mathrm{Au}-\mathrm{TiO}_{2}$ junction, which exhibited the enhanced photocatalytic activity owing to the fast vectorial electron transfer. ${ }^{[18]}$ 
Although the electron-transfer has been well studied, less attention has been paid to the holetransfer based system, which is very useful for the oxidation reaction.

It is well known that $\mathrm{TiO}_{2}$ has been used in photocatalysis largely due to its suitable valance-band position for oxidizing water to $\mathrm{O}_{2}$ with the low efficiency. ${ }^{[16,24-25]}$ The $\mathrm{IrO}_{\mathrm{x}^{-}}$ based samples have been regarded as the practical water oxidation catalysts with the fast kinetics and outstanding stability in $\mathrm{O}_{2}$ generation from water splitting. ${ }^{[5]}$ To ensure a highefficiency and stable water oxidation system, herein, we take advantages of using both $\mathrm{TiO}_{2}$ and $\mathrm{IrO}_{\mathrm{x}}$ to achieve the fast hole transfer and utilization by introducing a hole-transfer bridge, which consists of amorphous $\mathrm{TiO}_{2}\left(\mathrm{am}: \mathrm{TiO}_{2}\right)$ layer and metallic $\mathrm{Ir}$. The am: $\mathrm{TiO}_{2}$ is first introduced on $\mathrm{TiO}_{2}$ surface using developed method based on carbon nitride $(\mathrm{CN})$ corrosion. Then the obtained $\mathrm{TiO}_{2}$ sample $\left(\mathrm{am} @ \mathrm{TiO}_{2}\right)$ is employed to load $\mathrm{IrO}_{\mathrm{x}}$ via photo-deposition ${ }^{[26-}$ 27] and chemical reduction methods to form the four-layer of $\mathrm{TiO}_{2}-\mathrm{am}: \mathrm{TiO}_{2}-\mathrm{Ir}-\mathrm{IrO}{ }_{2}$ nanojunction system $\left(\mathrm{IrO}_{\mathrm{x}}-\mathrm{am} @ \mathrm{TiO}_{2}\right)$. Owing to the homojunction of $\mathrm{TiO}_{2}$ to am: $\mathrm{TiO}_{2}$, and the fast carrier transportation character of am: $\mathrm{TiO}_{2}$ layer, the interfacial resistance for the hole transfer is greatly reduced and thus the sample of $\mathrm{IrO}_{\mathrm{x}}-\mathrm{am} @ \mathrm{TiO}_{2}$ exhibited the highest photocatalytic water oxidation performance with the $\mathrm{O}_{2}$ generation rate of $143.6 \mu \mathrm{mol} / \mathrm{g} * \mathrm{~h}$ under the illumination of AM 1.5.

\section{Results and Discussion}

\subsection{Photocatalyst synthesis and characterization}




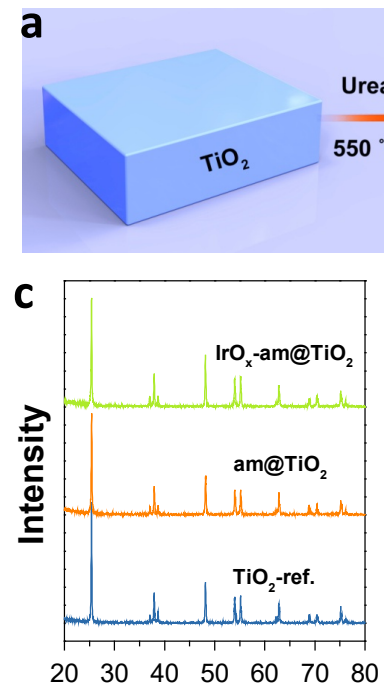

2 theta (deg.)
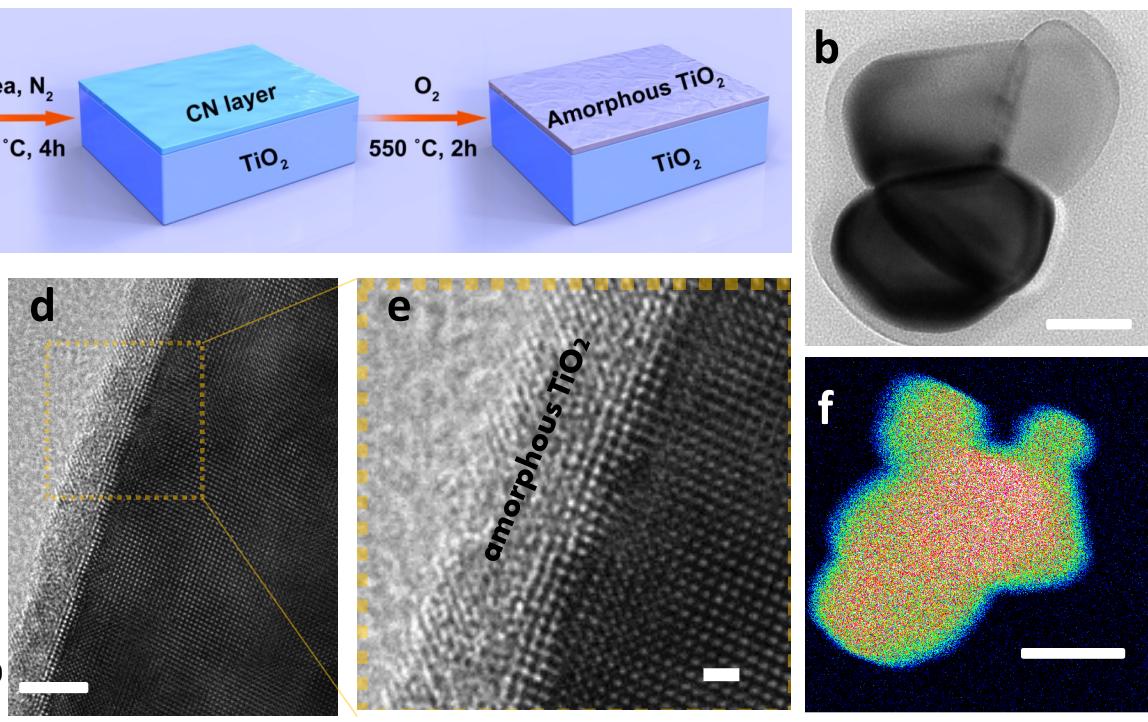

Figure 1. (a) Schematic illustration of the synthesis of am@TiO2 via two-step process. (b) TEM image of $\mathrm{CN}^{-T i O}{ }_{2}$ sample, scale bar, $100 \mathrm{~nm}$. (c) XRD patterns of the $\mathrm{TiO}_{2}$-ref, am@TiOz andIrO-am@TiO samples.(d) HRTEM image of am@TiO sample, scale bar,5 $\mathrm{nm}$ and (e) the corresponding magnified TEM, scale bar, $1 \mathrm{~nm}$. (f) The concentration distribution based on the STEM measurement of oxygen element of the sample of am@TiO2. Scale bar, $100 \mathrm{~nm}$.

The am@ $\mathrm{TiO}_{2}$ was synthesized by mixing anatase $\mathrm{TiO}_{2}$ and urea (mass ratio, 1:4), followed by two-step calcination process as shown in Figure 1a. The mixtures were treated at $550{ }^{\circ} \mathrm{C}$ in $\mathrm{N}_{2}$ atmosphere to obtain the compound of $\mathrm{g}-\mathrm{C}_{3} \mathrm{~N}_{4}$ and $\mathrm{TiO}_{2}\left(\mathrm{CN}-\mathrm{TiO}_{2}\right)$, which was confirmed by Fourier-transform infrared spectroscopy (FTIR) spectra (Figure S1a). Figure 1b shows the transmission electron microscope (TEM) image of $\mathrm{CN}-\mathrm{TiO}_{2}$ with the obvious $\mathrm{CN}$ layer. The sample of $\mathrm{CN}-\mathrm{TiO}_{2}$ was further annealed at $550{ }^{\circ} \mathrm{C}$ in air for $2 \mathrm{~h}$ to obtain the am@ $\mathrm{TiO}_{2}$, which showed no $\mathrm{g}_{-} \mathrm{C}_{3} \mathrm{~N}_{4}$ signals in the FTIR result (Figure S1a). Moreover, X-ray photoelectron spectroscopy (XPS) further confirmed that the $\mathrm{CN}$ was removed thoroughly (Figure S2). X-ray powder diffraction (XRD) patterns show the similar patterns of $\mathrm{CN}-\mathrm{TiO}_{2}$ and am@ $\mathrm{TiO}_{2}$ (Figure S1b), suggesting that the thickness of the surface amorphous layer was less. 
The reference sample of $\mathrm{TiO}_{2}\left(\mathrm{TiO}_{2}\right.$-ref) was synthesized under the same experimental condition in the absence of urea. XRD patterns of the am@ $\mathrm{TiO}_{2}$ and $\mathrm{TiO}_{2}$-ref in Figure 1c displayed the same peaks, suggesting the thin amorphous $\mathrm{TiO}_{2}$ layer, and the high resolution TEM (HRTEM) image further confirmed its ca. $5 \mathrm{~nm}$ thickness (Figure 1d-e). Moreover, their TEM images (Figure 1d and Figure S3) showed the similar particle size with the different surface state of with and without amorphous layer, confirming the $\mathrm{CN}$ component was the determinant factor for the formation of am@ $\mathrm{TiO}_{2}$ sample.

The element oxygen concentration distribution based on the $\mathrm{O}-\mathrm{K}$ ray intensity obtained from scanning transmission electron Microscope (STEM) was further measured to confirm the surface state of am@ $\mathrm{TiO}_{2}$. As shown in Figure 1f, more oxygen percentage of surface region than bulk part can be clearly observed, suggesting that there are abundant surface adsorbed $-\mathrm{OH}$ or $\mathrm{H}_{2} \mathrm{O}$ species. It should be noted that the thickness of the amorphous layer can be tuned by CN content as shown in Figure S4-S5. The defect (bulk and surface) information on $\mathrm{TiO}_{2}, \mathrm{TiO}_{2}$-ref and $\mathrm{am} @ \mathrm{TiO}_{2}$ was further studied by positron annihilation technique. The three-exponential fitted results show that the three samples exhibit the near life values with the percentages listed in Table S1, suggesting that no defect sites such as oxygen, titanium and line vacancies were introduced by the surface amorphous layer.

The $\mathrm{CN}$ corrosion mechanism for am@ $\mathrm{TiO}_{2}$ formation from $\mathrm{CN}-\mathrm{TiO}_{2}$ sample was studied by a Quasi in situ XPS measurement. $\mathrm{CN}-\mathrm{TiO}_{2}$ was treated to obtain five samples under $500{ }^{\circ} \mathrm{C}$ for different durations of 15, 30, 45, 60 and $90 \mathrm{~min}$. As shown in Figure S6a, there are obvious $\mathrm{Ti}^{3+}$ signals at the binding energy values of ca. 457.4 and $463.2 \mathrm{eV}^{[28-30]}$ for the first 60 minutes, with the sample treated after 30 min showing the highest intensity. For the signal of O 1s XPS results (Figure S6b), the samples exhibit the increased signal intensity of adsorbed $-\mathrm{OH}$ and $\mathrm{H}_{2} \mathrm{O}$ at ca. 532.3 and $533.8 \mathrm{eV}^{[29]}$, indicating that the treatment induced more surface oxygen vacancy sites, and this is consistent with the STEM result in Figure 1f. The $\mathrm{Ti}^{4+}$ ions of surface Ti-O layers receive the electrons from $\mathrm{N}^{3-}$ ions oxidation, and then 
form the $\mathrm{Ti}^{3+}$ sites with the nearby oxygen vacancies, which will adsorb water to produce the adsorbed $-\mathrm{OH}$, and then the surface disordered Ti-O layers forms.

$\mathrm{IrO}_{\mathrm{x}}-\mathrm{am} @ \mathrm{TiO}_{2}$ was synthesized via a two-step process, i.e. first photo-deposition and then chemical treatment by $\mathrm{H}_{2} / \mathrm{Ar}$ at $200{ }^{\circ} \mathrm{C}$. XRD pattern of the $\mathrm{IrO}_{\mathrm{x}}-\mathrm{am} @ \mathrm{TiO}_{2}$ suggests that the phase structure of the am@ $\mathrm{TiO}_{2}$ unchanged after $\mathrm{IrO}_{\mathrm{x}}$ loading (Figure 1c), and no obvious $\mathrm{IrO}_{\mathrm{x}}$-based XRD peaks, confirming the low loaded content. Raman spectra of samples of $\mathrm{TiO}_{2}$-ref, am@ $\mathrm{TiO}_{2}$ and $\mathrm{IrO}_{\mathrm{x}}$-am@ $@ \mathrm{TiO}_{2}$ show the main peaks loaded at 395, 515 and $635 \mathrm{~cm}^{-}$ ${ }^{1}$ (Figure S7a), which are assigned to the typical $\mathrm{E}_{\mathrm{g}}, \mathrm{A}_{1 \mathrm{~g}}$ and $\mathrm{B}_{1 \mathrm{~g}}$ of Raman vibration modes. ${ }^{[29]}$ The relative intensity of $\mathrm{B}_{1 \mathrm{~g}} / \mathrm{E}_{\mathrm{g}}$ of am $@ \mathrm{TiO}_{2}$ sample is decreased compared with $\mathrm{TiO}_{2}$-ref sample. It has been reported that the $\mathrm{E}_{\mathrm{g}}$ and $\mathrm{B}_{1 \mathrm{~g}}$ can be attributed to the symmetric stretching and bending vibration patterns of O-Ti-O ${ }^{[29]}$ The changes of $\mathrm{B}_{1 \mathrm{~g}} / \mathrm{E}_{\mathrm{g}}$ suggest that the coordinate form of surface O-Ti-O bonds has been disorganized by the non-defective sites. FTIR results in Figure S7b show the similar curves. However, the sample of am@ $\mathrm{TiO}_{2}$ or $\mathrm{IrO}_{\mathrm{x}}-\mathrm{am} @ \mathrm{TiO}_{2}$ exhibits a stronger intensity for the peaks at 1600 and $3400 \mathrm{~cm}^{-1}$ assigned to adsorbed $-\mathrm{OH}$ groups ${ }^{[5]}$ in comparison to the $\mathrm{TiO}_{2}$-ref, further confirming the more surface disordered Ti-O arrangement for am@ $\mathrm{TiO}_{2}$-based samples. It should be mentioned that $\mathrm{IrO}_{\mathrm{x}^{-}}$ am@ $\mathrm{TiO}_{2}$ exhibits a similar $-\mathrm{OH}$ group intensity to that of bare am@ $\mathrm{TiO}_{2}$, suggesting that the loading of $\mathrm{IrO}_{\mathrm{x}}$ nanoparticles does not change the surface $-\mathrm{OH}$ sites on the am@ $\mathrm{TiO}_{2}$ surface. Moreover, the surface areas were measured by $\mathrm{N}_{2}$ adsorption and desorption as shown in Figure S8, in which the three samples exhibited the BET surface areas of 10.7, 10.7 and $10.6 \mathrm{~m}^{2} / \mathrm{g}$, respectively. No obvious difference was detected, implying that the difference of $-\mathrm{OH}$ amount of the samples came from the surface properties.

Figure 2a and Figure S8 show the TEM image of $\mathrm{IrO}_{\mathrm{x}}-\mathrm{am} @ \mathrm{TiO}_{2}$, the homogeneous nanosized (ca. $1.5 \mathrm{~nm}$ ) dark dots are evenly distributed on the $\mathrm{TiO}_{2}$ surface. However, the reference sample of $\mathrm{IrO}_{\mathrm{x}}-\mathrm{TiO}_{2}$-ref shows the obvious aggregated particles of loaded $\mathrm{IrO}_{\mathrm{x}}$ (Figure S9), suggesting that the surface $\mathrm{am}: \mathrm{TiO}_{2}$ layer help the homo-dispersion of $\mathrm{IrO}_{\mathrm{x}}$ 
particles. The HRTEM image in Figure 2b shows that the $\mathrm{IrO}_{\mathrm{x}}$ is loaded on amorphous layer. The yellow magnified region shows the clear interplanar spacing value of $0.22 \mathrm{~nm}$ attributed to the tetragonal $\mathrm{IrO}_{2}$ (200) (Figure 2c), however, the bulk region of this $\mathrm{IrO}_{\mathrm{x}}$ particle contacted with am@ $\mathrm{TiO}_{2}$ seems disparate and belongs to metallic Ir, the $\mathrm{Ir}-\mathrm{IrO}_{2}$ core-shell structure is formed by the $\mathrm{H}_{2}$ reduction and air oxidation. The high-angle annular dark field (HAADF) STEM image further confirms the uniform size $(c a .3 \mathrm{~nm})$ of bright dots on the support (Figure 2d), and the corresponding element mapping suggests that the detected dots are Ir-based samples. The line mapping shows the weak Ir elemental signal, confirming the low content of loaded $\mathrm{IrO}_{\mathrm{x}}$ (Figure 2e-f). Moreover, a particle size of around $3 \mathrm{~nm}$ of the lorded $\mathrm{IrO}_{\mathrm{x}}$ can be obtained (Figure S10). The elemental mapping on the reference sample of $\mathrm{IrO}_{\mathrm{x}}-\mathrm{TiO}_{2}$-ref was also carried out (Figure S11). The relative large particle size (ca. $\left.10 \mathrm{~nm}\right)$ of $\mathrm{IrO}_{\mathrm{x}}$ with the agglomeration can also be found.
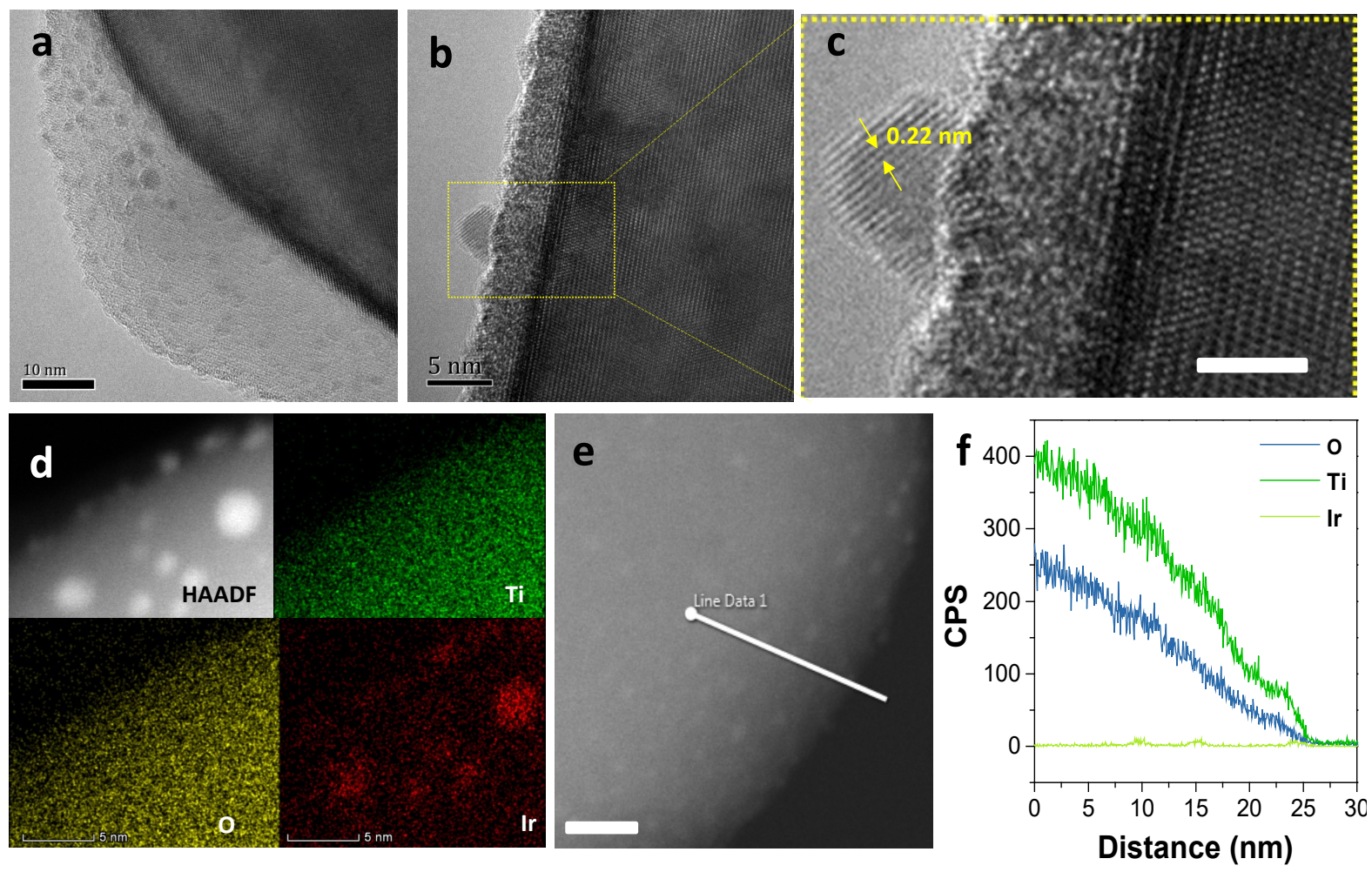

Figure 2. TEM analysis of the IrOx-am@TiO sample. (a) TEM image, (b) HRTEM image, and (c) the corresponding magnified region with the clear lattice fringes, scale bar, $2.5 \mathrm{~nm}$. 
(d) HAADF-STEM image and the elemental mapping. (e) STEM result with the line mapping, scale bar, $10 \mathrm{~nm}$, and (f) the corresponding elemental line mapping results.

The optical characteristics of the $\mathrm{TiO}_{2}$-ref, am@ $\mathrm{TiO}{ }_{2}$ and $\mathrm{IrO}_{\mathrm{x}}-\mathrm{am} @ \mathrm{TiO}_{2}$ were studied via using UV-Vis-NIR absorption spectroscopy and room-temperature photoluminescence (PL) spectroscopy. As shown in Figure S12a, all three samples showed the same absorption cut-off edge of $c a .388 \mathrm{~nm}$, which is a typical optical property of anatase $\mathrm{TiO}_{2} \cdot{ }^{[28-30}$ However, for the am@ $\mathrm{TiO}_{2}$-based samples, the obvious tail absorption can be detected and the loading of $\mathrm{IrO}_{\mathrm{x}}$ nanoparticles can further increase the absorption, suggesting that the surface amorphous $\mathrm{TiO}_{2}$ layer and loaded $\mathrm{IrO}_{\mathrm{x}}$ are helpful for the utilization of incident photons. The band gaps of the $\mathrm{TiO}_{2}$-ref, am@ $\mathrm{TiO}_{2}$ and $\mathrm{IrO}_{\mathrm{x}}$-am $@ \mathrm{TiO}_{2}$ were measured to be 3.20, 3.15 and 3.07 eV (Figure S12b), respectively. The PL spectra was measured at the excitation wavelength of $295 \mathrm{~nm}$. As shown in Figure S12c, all three samples showed the obvious signals in the range of 350 to $500 \mathrm{~nm}$ and the sample of $\mathrm{TiO}_{2}$-ref gave the highest intensity, followed by am@ $\mathrm{TiO}_{2}$ and $\mathrm{IrO}_{\mathrm{x}}-\mathrm{am} @ \mathrm{TiO}_{2}$, suggesting that the amorphous layer and $\mathrm{IrO}_{\mathrm{x}}$ loading can boost the separation of photogenerated carriers.
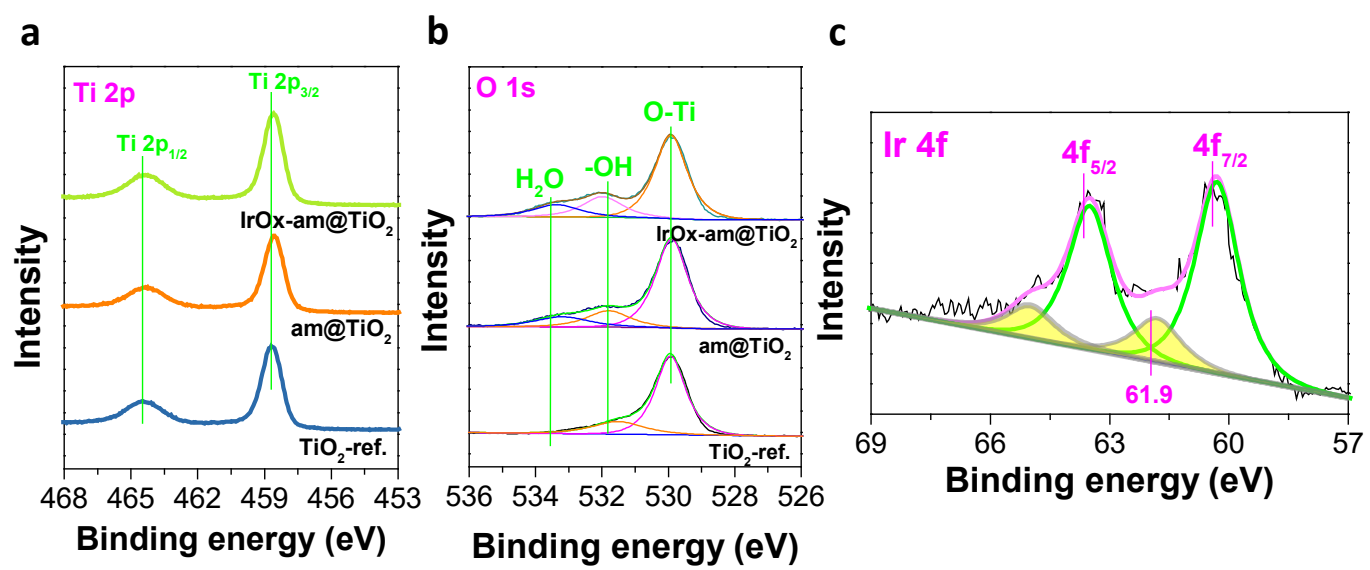

Figure 3. XPS analysis of the TiO2-ref, am@TiOz and IrO $\mathrm{T}_{x}-\mathrm{am} @ \mathrm{TiO}_{2}$. (a) Ti 2p, (b) O 1s and (c) Ir $4 f$. 
Figure 3a shows the Ti 2p XPS spectrum of the samples of $\mathrm{TiO}_{2}$-ref, am $@ \mathrm{TiO}_{2}$ and $\mathrm{IrO}_{\mathrm{x}^{-}}$ am@ $\mathrm{TiO}_{2}$, two main peaks at 458.7 and $464.4 \mathrm{eV}$, which can be assigned to the $\mathrm{Ti}^{4+} 2 \mathrm{p}_{3 / 2}$ and $2 \mathrm{p}_{1 / 2},{ }^{[28-30]}$ respectively, can be found. The fitted peak locations of the three samples are 458.7, 458.55 and $458.6 \mathrm{eV}$ with the values of full width at half maximum (FWHM) of 1.038, 1.028 and $1.034 \mathrm{eV}$ (Figure S13), suggesting that there are no $\mathrm{Ti}^{3+}$ species in the studied samples. This result is also consistent with the above analysis about the material preparation mechanism in Figure S6. Figure 3b shows the corresponding O 1s XPS spectra with the three peaks loaded at 529.9, 531.9 and $533.5 \mathrm{eV}$, which are assigned to Ti-O, adsorbed -OH groups and water molecules, ${ }^{[29]}$ respectively. However, the sample of $\mathrm{TiO}_{2}$-ref shows almost no adsorbed water signal (Figure S14). The increased -OH group signals are consistent with FTIR results (Figure S7b) and suggest that amorphous $\mathrm{TiO}_{2}$ layer and $\mathrm{IrO}_{\mathrm{x}}$ can facilitate the water adsorption. The Ir 4f XPS spectrum of $\mathrm{IrO}_{\mathrm{x}}-\mathrm{am} @ \mathrm{TiO}_{2}$ shows two main characteristic peaks centered at 60.3 and $63.5 \mathrm{eV}$ (Figure 3c), which are assigned to the $\operatorname{Ir}^{0} 4 \mathrm{f}_{7 / 2}$ and $4 \mathrm{f}_{5 / 2}$, ${ }^{32]}$ respectively. Moreover, there are two weak peaks at 61.9 and $65.1 \mathrm{eV}$ assigned to the $\mathrm{Ir}^{4+}$ $4 \mathrm{f}_{7 / 2}$ and $4 \mathrm{f}_{5 / 2},{ }^{[31-32]}$ respectively. The result of $\mathrm{Ir}$ valence state of surface $\mathrm{IrO}_{\mathrm{x}}$ particles consisting of $4+$ and 0 , is in agreement with HRTEM analysis (Figure 2c). The relative content of $\mathrm{IrO}_{2}$ to metallic Ir was calculated to be $23.9 \%$ based on the peak area integral. It has been reported that the surface $\mathrm{IrO}_{2}$-based materials can be changed into Ir hydroxyls, which are proven to be useful for the generation of OER intermediates. ${ }^{[32]}$ Thus, the $\operatorname{Ir}^{0}$ species receive charge carriers from the amorphous $\mathrm{TiO}_{2}$ and then transfer them to the $\mathrm{IrO}_{\mathrm{x}}$ for OER steps.

\subsection{Photocatalytic water oxidation performance}



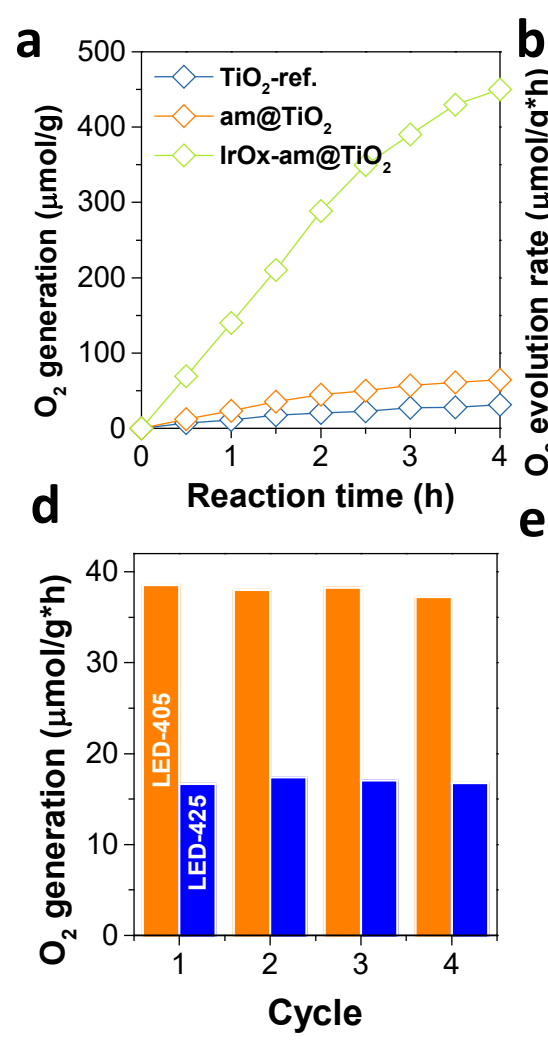

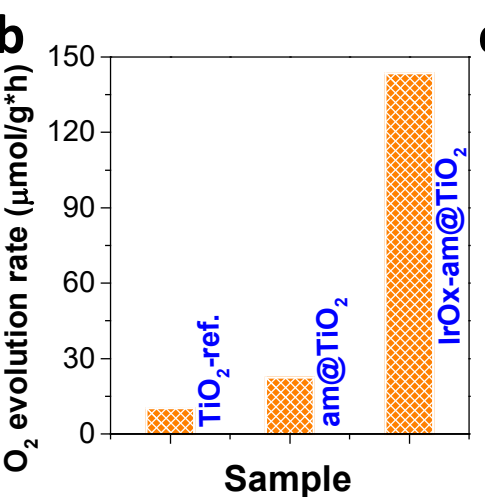

e

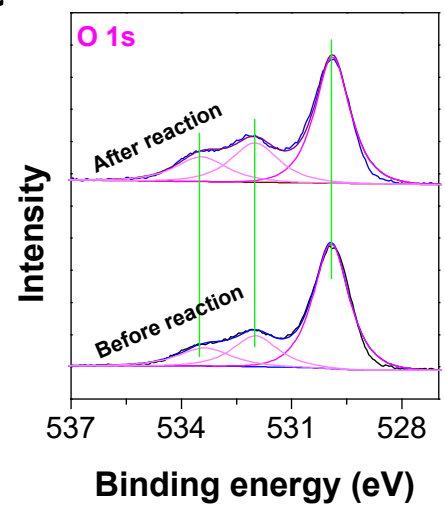

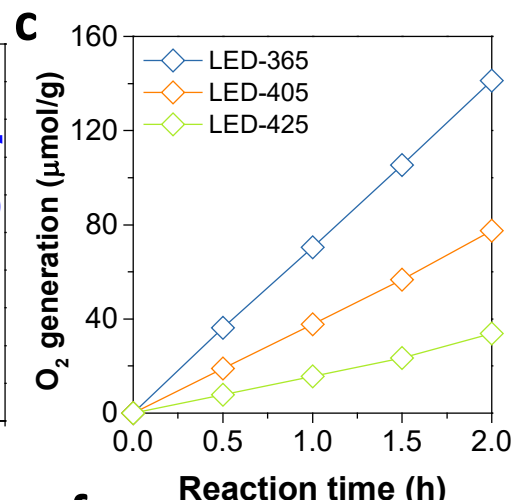

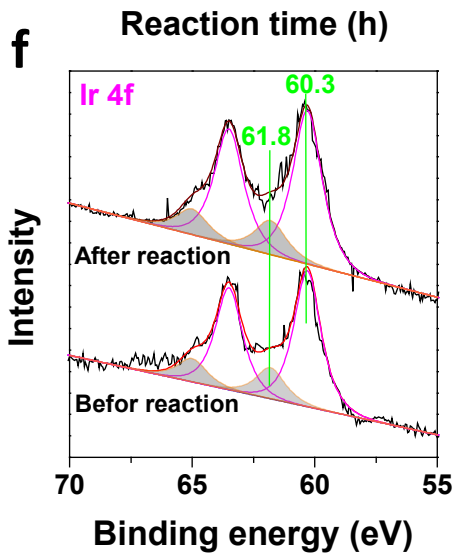

Figure 4. Photocatalytic water oxidation performance of $\mathrm{IrO}_{x}$-am@TiO $\mathrm{Tample}_{2}$ (a) $\mathrm{O}_{2}$ generation values of TiO2-ref, am@TiO2 and IrOx-am@TiO2 samples measured under the illumination of $A M 1.5$ and (b) the corresponding $\mathrm{O}_{2}$ generation. (c) $\mathrm{O}_{2}$ generation values of IrO-am@TiO sample under three LED lamp illuminations: LED-365,LED-405 and LED425. (d) The stability measurement of IrOx-am@TiO2 under visible-light conditions of LED405 and LED-425. (e) $O \mathrm{Is}$ and (f) Ir 4f XPS spectra of IrO-am@TiO $\mathrm{O}_{2}$ before and after reaction. All the $\mathrm{O}_{2}$ evolution experiments were carried out in $\mathrm{AgNO}_{3}(0.01 \mathrm{~g} / \mathrm{mL})$ solution.

The photocatalytic water oxidation performance of $\mathrm{IrO}_{\mathrm{x}}-\mathrm{am} @ \mathrm{TiO}_{2}$ was conducted to verify the advantage of hole-transfer bridge for transfer of holes. The online gas chromatography (GC) signals show that the $\mathrm{O}_{2}$ is indeed generated under the illumination of simulated sunlight (AM 1.5) (Figure S15). The $\mathrm{O}_{2}$ generation rates of the $\mathrm{TiO}_{2}$-ref, am $@ \mathrm{TiO}_{2}$ and $\mathrm{IrO}_{\mathrm{x}^{-}}$ am@ $\mathrm{TiO}_{2}$ are illustrated in Figure 4a and Figure S16, in which the sample of $\mathrm{IrO}_{\mathrm{x}}-\mathrm{am} @ \mathrm{TiO}_{2}$ giving the best activity. Typically, the $\mathrm{O}_{2}$ evolution rates were $10.3,22.4$ and $143.6 \mu \mathrm{mol} / \mathrm{g} * \mathrm{~h}$ for the $\mathrm{TiO}_{2}$-ref, am@ $\mathrm{TiO}_{2}$ and $\mathrm{IrO}_{\mathrm{x}}-\mathrm{am} @ \mathrm{TiO}_{2}$, respectively (Figure 4b). It should be noted that the latter two samples gave around 2.16 and 13.9 times higher than $\mathrm{TiO}_{2}$-ref, confirming 
that the amorphous $\mathrm{TiO}_{2}$ layer and $\mathrm{IrO}_{\mathrm{x}}$ loading are effective in separating the photogenerated carriers and promoting the surface water oxidation processes. Moreover, the $\mathrm{IrO}_{\mathrm{x}}$ loading content plays a vital role for the final optimal $\mathrm{O}_{2}$ evolution (Figure $\mathbf{S 1 7 a}$ ). The $1.5 \% \mathrm{IrO}_{\mathrm{x}^{-}}$ am@ $\mathrm{TiO}_{2}$ sample showed the highest performance. We also synthesized the two reference samples of $\mathrm{IrO}_{\mathrm{x}}-\mathrm{TiO}_{2}$-ref and $\mathrm{IrO}_{\mathrm{x}}-\mathrm{am} @ \mathrm{TiO}_{2}-1$, which were synthesized via the same preparation process with $\mathrm{IrO}_{\mathrm{x}}$-am $@ \mathrm{TiO}_{2}$ but using $\mathrm{TiO}_{2}$-ref as supporter and in $\mathrm{N}_{2}$ atmosphere, respectively. The corresponding photocatalytic water oxidation performance can be found in Figure S19. Clearly, the activity of $\mathrm{IrO}_{\mathrm{x}}-\mathrm{am} @ \mathrm{TiO}_{2}-1$ or $\mathrm{IrO}_{\mathrm{x}}-\mathrm{TiO}_{2}$-ref is lower than the sample of $\mathrm{IrO}_{\mathrm{x}}-\mathrm{am} @ \mathrm{TiO}_{2}$, suggesting that the surface amorphous $\mathrm{TiO}_{2}$ layer can be helpful for the separation and migration of photogenerated carriers. Moreover, the sample of $\mathrm{IrO}_{\mathrm{x}^{-}}$ am@ $\mathrm{TiO}_{2}-1$ exhibits a better activity than $\mathrm{IrO}_{\mathrm{x}}-\mathrm{TiO}_{2}$-ref, further confirming that the surface amorphous $\mathrm{TiO}_{2}$ layer is helpful for the carrier interface migration across $\mathrm{TiO}_{2}$ to $\mathrm{IrO}_{\mathrm{x}}$.

Next, the photocatalytic performance of the $\mathrm{IrO}_{\mathrm{x}}-\mathrm{am} @ \mathrm{TiO}_{2}$ was measured under the monochromatic incident illumination to investigate the apparent quantum/conversion yield (AQY). As shown in Figure 4c, the linear increase in the $\mathrm{O}_{2}$ generation as a function of reaction times can be observed under the illumination of the three monochromatic lamps of LED-365, 405 and 425, suggesting that the $\mathrm{IrO}_{\mathrm{x}}-\mathrm{am} @ \mathrm{TiO}_{2}$ is activated not only under UV condition of LED-365, but also the visible-light of LED-405 or LED-425. The $\mathrm{O}_{2}$ evolution rates were $70.3,38.56$ and $16.66 \mu \mathrm{mol} / \mathrm{g} * \mathrm{~h}$ for the LED-365, 405 and 425 , respectively. The AQY can be calculated according to the following equation: $A Q Y=\left(4 * \mathrm{O}_{2}\right.$ molecules)/(number of incident photons) $* 100 \%$. As shown in Figure S17b, the calculated AQY values were $38.4 \%, 18.9 \%$ and $7.82 \%$ under the illumination of LED-365, 405 and 425 , respectively. Please note that the surface disordered Ti-O layers and the loading of $\mathrm{Ir}-\mathrm{IrO}_{2}$ nanoparticles are responsible for the visible-light absorption [33-34].

However, for the $\mathrm{TiO}_{2}$-ref and am $@ \mathrm{TiO}_{2}$, the former shows almost no activity under LED405 and LED-425 while the latter exhibits considerable $\mathrm{O}_{2}$ evolution under the illumination of 
above two lamps (Figure S18). This is consistent with the above UV-vis absorption results (Figure S12a), further suggesting that the surface amorphous $\mathrm{TiO}_{2}$ layer and loaded $\mathrm{IrO}_{\mathrm{x}}$ nanoparticles can assist to the effective utilization of visible-light photons.

The stability of the $\mathrm{IrO}_{\mathrm{x}}-\mathrm{am} @ \mathrm{TiO}_{2}$ under the visible-light condition (LED-405 and 425) was studied. Almost no change in the activity was detected over four cycles of measurements (Figure S19 and Figure 4d). The chemical valence states after the stability test were further measured to confirm unchanged surface state. As shown in Figure 4e, the O 1s XPS spectra exhibits the same peak location before and after the long-time measurement, suggesting the stable chemical environment. However, the proportions of surface $\mathrm{OH}$ group and adsorbed water were $20.9 \%$ and $15.3 \%$ before the stability test based on the area integral, while these values increased to $24.2 \%$ and $17.2 \%$ after the reaction, respectively (Table S2). Considering the fact that no peak position is shifted, these increased surface $\mathrm{OH}$ groups and $\mathrm{H}_{2} \mathrm{O}$ molecules can be attributed to the weakly adsorbed components during the testing. Moreover, the Ir 4f XPS spectra before and after the reaction suggest no shift in the peak positions (Figure 4f). The relative ratio of $\mathrm{IrO}_{2}$ to metallic Ir based on the area integral after the stability test is calculated to be $23.79 \%$, close to the previous value (Figure 3c), suggesting that the surface $\mathrm{IrO}_{2}$ layer is very chemical stabile during OER processes, and also acts as a protective layer for the inner metal. Thus, it can be preliminary concluded that the photogenerated holes firstly transferred across the amorphous $\mathrm{TiO}_{2}$ layer to metal $\mathrm{Ir}$, and then reach to the surface $\mathrm{IrO}_{2}$ for finishing following multi-step OER steps without changing the surface $\mathrm{IrO}_{2}$ chemical state.

\subsection{Catalytic mechanism investigation}



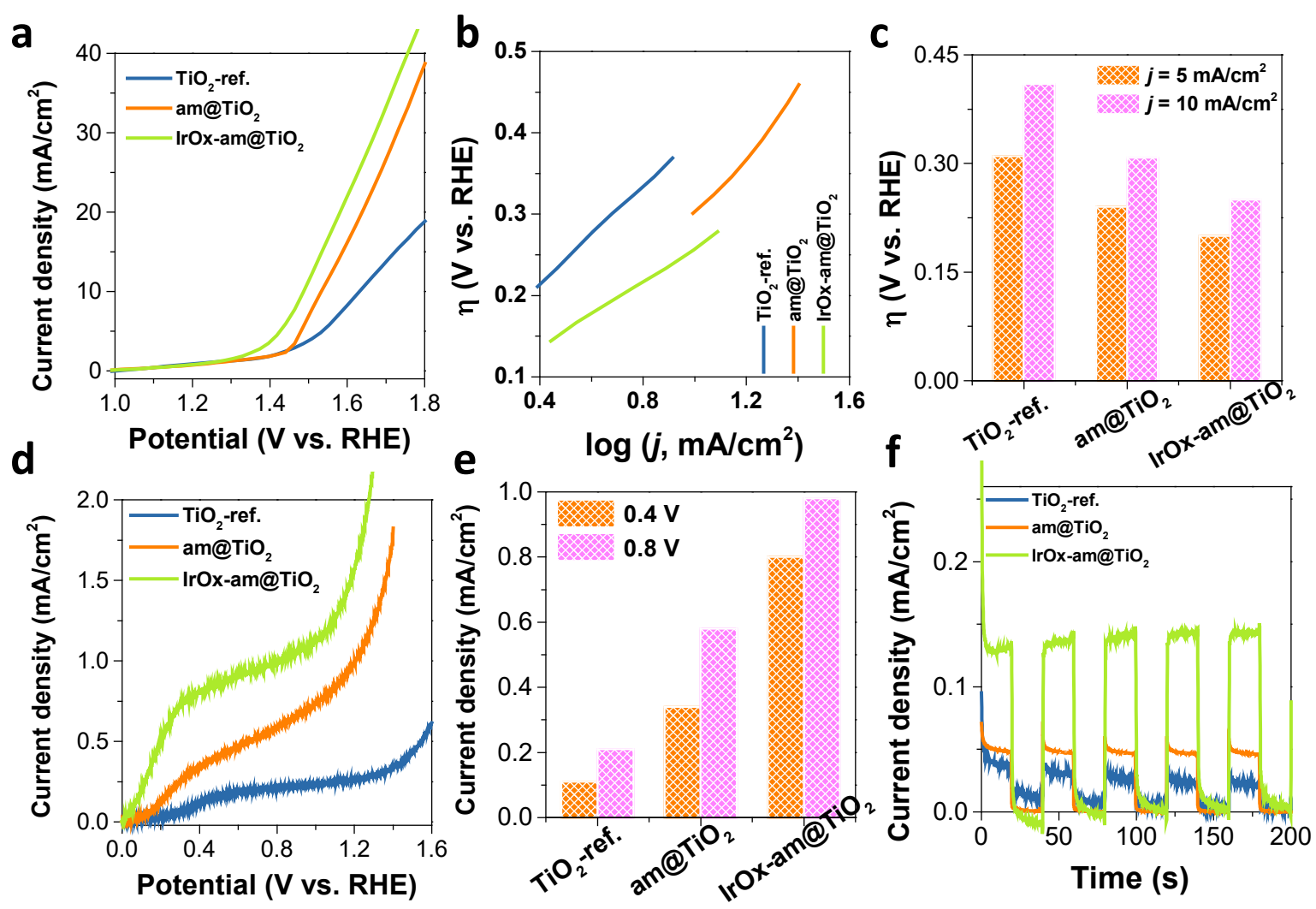

Figure 5. Electrochemical properties of the samples. (a) Polarization curves of the $\mathrm{TiO}_{2}$-ref, am@TiO 2 and IrOx-am@TiO $\mathrm{Ti}_{2}$; and (b) the corresponding Tafel plots and (c) the overpotential values at the current density values of 5 and $10 \mathrm{~mA} / \mathrm{cm}^{2}$. (d) Photocurrent responses of the three recorded under the illumination of AM 1.5, and (e) the corresponding current density values measured under the two bias voltages of $0.4 \mathrm{~V}$ and $0.8 \mathrm{~V}$. (f) Transient responses of photocurrents of the three samples measured under the illumination of LED-405 lamp. All the measurements were carried out in $0.5 \mathrm{M} \mathrm{Na}_{2} \mathrm{SO}_{4}$ solution.

The inherent characteristics of photocatalytic process is the interfacial and surface reactions. The photogenerated charge carriers migrate to the surface reaction sites and then take part in the corresponding reactions. ${ }^{[35-36]}$ The electrocatalytic performances of the $\mathrm{TiO}_{2}$-ref, am $@ \mathrm{TiO}_{2}$ and $\mathrm{IrO}_{\mathrm{x}}-\mathrm{am} @ \mathrm{TiO}_{2}$ were further investigated to gain insight into the internal kinetics of the enhanced photocatalytic water oxidation. The polarization curves were first studied in a neutral solution (Figure 5a). All three samples showed considerable current responses in the voltage ranges of 1.3 to $1.8 \mathrm{~V}$ (vs. RHE), suggesting that these $\mathrm{TiO}_{2}$-based samples can 
achieve the electrolysis of water. It should be noted that the $\mathrm{IrO}_{\mathrm{x}}-\mathrm{am} @ \mathrm{TiO}_{2}$ exhibits the first current response, followed by am $@ \mathrm{TiO}_{2}$ and then $\mathrm{TiO}_{2}$-ref, confirming that the introduction of surface amorphous $\mathrm{TiO}_{2}$ layer and $\mathrm{IrO}_{\mathrm{x}}$ loading can boost the water splitting.

The corresponding Tafel plots, which are useful for exploring the reaction kinetics during the electrocatalytic process, are shown in Figure 5b. The calculated Tafel slopes for the $\mathrm{TiO}_{2}-$ ref, am@ $\mathrm{TiO}_{2}$ and $\mathrm{IrO}_{\mathrm{x}}-\mathrm{am} @ \mathrm{TiO}_{2}$ were 342, 325 and $203 \mathrm{mV} / \mathrm{dec}$, respectively. The overpotential $(\eta, \mathrm{mV})$ is the other vital parameter for investigating the difficult degree of the water oxidation. The $\mathrm{TiO}_{2}$-ref sample shows the largest overpotential value at the current densities $(j)$ of 5 or $10 \mathrm{~mA} / \mathrm{cm}^{2}$ (Figure 5c), promisingly, both am@ $\mathrm{TiO}_{2}$ and $\mathrm{IrO}_{\mathrm{x}}-\mathrm{am} @ \mathrm{TiO}_{2}$ exhibit clear decreases in the overpotential values. Particularly, the measured $\eta$ values of the TiO2-ref, am@ $\mathrm{TiO}_{2}$ and IrOx-am@ $\mathrm{TiO}_{2}$ were 410, 308 and $250 \mathrm{mV}$, respectively to achieve $10 \mathrm{~mA} / \mathrm{cm}^{2}$ current densities. The smallest $\eta$ and the fastest reaction kinetics of the $\mathrm{IrO}_{\mathrm{x}^{-}}$ am@ $\mathrm{TiO}_{2}$ co-determine the excellent water splitting performance.

The photoelectric properties were also studied to confirm the excellent performance of photogenerated carrier migration and surface reaction under the illumination of simulated sunlight. All three samples $\left(\mathrm{TiO}_{2}\right.$-ref, am@ $\mathrm{TiO} 2$ and $\left.\mathrm{IrO}_{\mathrm{x}}-\mathrm{am} @ \mathrm{TiO}_{2}\right)$ exhibited considerable photocurrent responses at the potential range of 0 to $1.6 \mathrm{~V}$ (vs. RHE) (Figure 5d), in particular, the $\mathrm{IrO}_{\mathrm{x}}-\mathrm{am} @ \mathrm{TiO}_{2}$ obtained the highest current value as compared to the am@ $\mathrm{TiO}_{2}$ and $\mathrm{TiO}_{2}$-ref, suggesting that the amorphous $\mathrm{TiO}_{2}$ layer and $\mathrm{IrO}_{\mathrm{x}}$ loading could timely extract photogenerated holes for the surface reaction. The current values of three samples $\left(\mathrm{TiO}_{2}\right.$-ref, am@ $\mathrm{TiO}_{2}$ and $\left.\mathrm{IrO}_{\mathrm{x}}-\mathrm{am} @ \mathrm{TiO}_{2}\right)$ had been compared under the bias voltage values of 0.4 and $0.8 \mathrm{~V}$ (Figure 5e) with the sample of $\mathrm{IrO}_{\mathrm{x}}-\mathrm{am} @ \mathrm{TiO}_{2}$ achieving the highest current density value.

Furthermore, the applied bias photon-current efficiency (ABPE) can be obtained based on the following equation:

$$
\mathrm{ABPE}=\left[j \times\left(1.23-\mathrm{V}_{\text {app }}\right)\right] / \mathrm{P}_{\text {light }}
$$


where $j$ is the photocurrent density $\left(\mathrm{mA} / \mathrm{cm}^{2}\right) ; \mathrm{V}_{\text {app }}$ is the applied bias (vs. RHE), and $\mathrm{P}_{\text {light }}$ is the incident light intensity $\left(100 \mathrm{~mW} / \mathrm{cm}^{2}\right)$. It can be clearly seen that $\mathrm{IrO}_{\mathrm{x}}-\mathrm{am} @ \mathrm{TiO}_{2}$ obtained the highest ABPE value of $0.53 \%$ at the bias voltage of $0.3 \mathrm{~V}$, followed by $0.22 \%$ at $0.41 \mathrm{~V}$ for the am@ $\mathrm{TiO}_{2}$ and $0.12 \%$ at $0.52 \mathrm{~V}$ for the $\mathrm{TiO}_{2}$-ref sample (Figure S20a). This further confirms that the introduction of surface $\mathrm{TiO}_{2}$ and $\mathrm{IrO}_{\mathrm{x}}$ can facilitate fast and high photoncurrent conversion.

The transient response of the photo-to-current was further carried out as it is very important for explaining the separation ability of photogenerated carriers. As shown in Figure 5f, all samples showed the typical current-time (I-t) signals when illuminated using a LED-405 lamp (and LED-425 condition in Figure S20b). No significant response delay was detected, suggesting the typical semiconductor property of the $\mathrm{TiO}_{2}$-based samples. However, for the $\mathrm{TiO}_{2}$-ref and am@ $\mathrm{TiO}_{2}$, some current recovery delay can be detected (Figure S21). This suggests that the charge carriers are generated under illumination, and the current values are originated from the surface chemical reaction. However, for the $\mathrm{TiO}_{2}$-ref or am@ $\mathrm{TiO}_{2}$, the surface reaction is not completed owing to the surface reaction dynamics.

The density functional theory (DFT) calculations were further carried out to obtain more information about the carriers migration of am@ $\mathrm{TiO}_{2}$-based samples. The charge density difference shows that the interface region of crystal and amorphous $\mathrm{TiO}_{2}$ is the electron collection center (Figure 6a), and thus the surface reaction sites i.e. catalyst-solution interface exhibit the electron deficiency, which can promote the water or - $\mathrm{OH}$ groups adsorption. The projected density of states (PDOS) of the above model were next conducted to study the promotion of carrier separation. As shown in Figure 6b, an obvious defect energy level in the bandgap of the PDOS of amorphous $\mathrm{TiO}_{2}$ can be observed, confirming the presence of many defect sites, which will provide more free carriers. According to the merit of electron accumulation in crystal and amorphous $\mathrm{TiO}_{2}$ interface, the am@ $\mathrm{TiO}_{2}$ layer will be in such a 
condition of polarization, that is, it works as the hole transfer bridge and then can promote the photocatalytic oxidation performance.
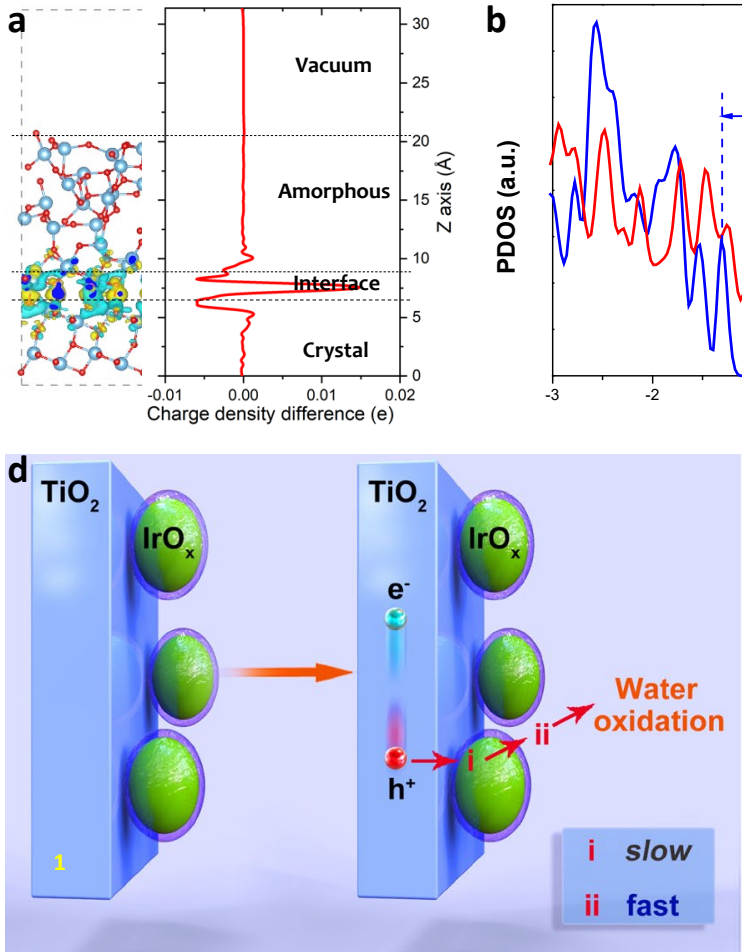

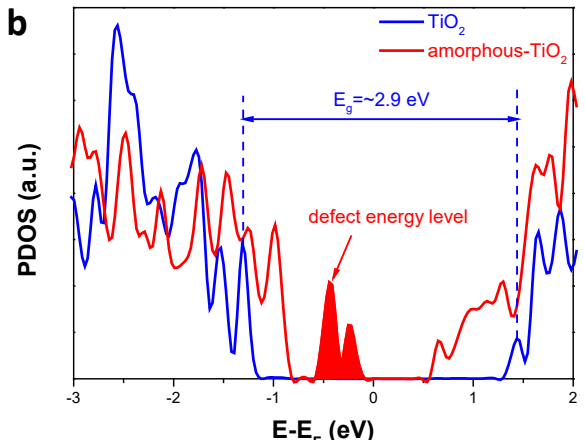

$E-E_{F}(e V)$
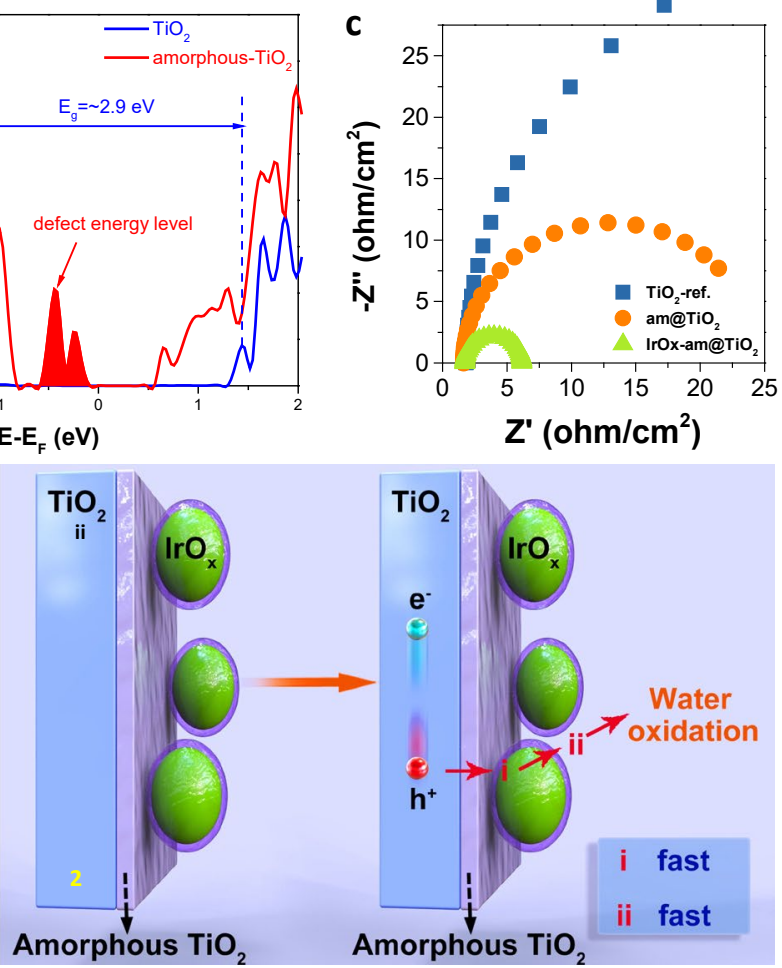

Figure 6. Interface study on the samples. (a) Charge density difference and (b) the corresponding PDOS spectra of am@TiOz sample. (c) EIS spectra of the TiO2-ref, am@TiO2 and $\mathrm{IrO}_{x}$-am@TiO $\mathrm{T}_{2}$ (d) Photocatalytic water oxidation mechanism: (1) reference IrO $\mathrm{O}_{x}-\mathrm{TiO}_{2}$ sample and (2) IrOx-am@TiO sample.

The surface reaction refers to carrier migration resistance can be studied via electrochemical impedance spectroscopy (EIS) under dark and illumination conditions. The samples of $\mathrm{TiO}_{2}-$ ref., am@ $\mathrm{TiO}_{2}$ and $\mathrm{IrO}_{\mathrm{x}}-\mathrm{am} @ \mathrm{TiO}_{2}$ show the typical semicircles with the reduced radiuses (Figure 6c and Figure S22), suggesting that the surface amorphous $\mathrm{TiO}_{2}$ layer and $\mathrm{IrO}_{\mathrm{x}}$ loading can reduce the resistance of the carrier interface migration. The fitted results based on the circuit diagram (Figure S23) can be found in Table S3. The parameters of R1 and R2 are known as the carrier resistance across the electrode-to-catalyst and catalyst-to-solution interfaces, ${ }^{[23]}$ respectively. Clearly, some slight changes in the R1 values can be observed, while the reduction of $\mathrm{R} 2$ values appears when comparing the $\mathrm{TiO}_{2}$-ref and $\mathrm{IrOx}-\mathrm{am} @ \mathrm{TiO}_{2}$. 
Notably, the R2 value of the $\mathrm{TiO}_{2}$-ref was measured to be $360 \mathrm{ohm} / \mathrm{cm}^{2}$, which is almost 6 times higher than that of the am@ $\mathrm{TiO}_{2}$, further confirming that the adsorbed water or -OH group can lower the energy barrier of the carriers migration.

The mechanism of our photocatalytic water oxidation can be summarized as follows: $\mathrm{TiO}_{2}$ nanoparticles generate electron-hole pairs upon illumination; and the holes are transferred to the $\mathrm{IrO}_{\mathrm{x}}$ sites across amorphous $\mathrm{TiO}_{2}$ layer, which acts as a hole-transfer bridge. In the absence of this bridge, the interface resistance between $\mathrm{TiO}_{2}$ and $\mathrm{IrO}_{\mathrm{x}}$ is high and thus the carrier migration rate is slow (Figure 6d-1). However, in the case of $\mathrm{IrO}_{\mathrm{x}}-\mathrm{am} @ \mathrm{TiO}_{2}$, the $\mathrm{TiO}_{2}$ layer weakens the Schottky barrier and the photogenerated holes are rapidly travelled across the $\mathrm{TiO}_{2}$ layer to $\mathrm{Ir}$ and then $\mathrm{IrO}_{\mathrm{x}}$ for completing the water oxidation (Figure 6d-2).

\section{Conclusions}

In this work, a four layer i.e. $\mathrm{TiO}_{2}$-am: $\mathrm{TiO}_{2}-\mathrm{Ir}-\mathrm{IrO}_{2}$ material with a hole-transfer bridge is designed using a facile two-step synthesis method. With the support of am: $\mathrm{TiO}_{2}-\mathrm{Ir}$, the photogenerated holes of $\mathrm{TiO}_{2}$ are transferred to the water oxidation sites of $\mathrm{IrO}_{2}$ promptly, and induce a photocatalytic $\mathrm{O}_{2}$ generation rate of $143.6 \mu \mathrm{mol} / \mathrm{g} * \mathrm{~h}$ under the illumination of AM 1.5. Moreover, the sample of $\mathrm{IrO}_{\mathrm{x}}-\mathrm{am} @ \mathrm{TiO}_{2}$ exhibits an AQY value of $18.99 \%$ LED-405 illumination. DFT calculations confirm that the surface am: $\mathrm{TiO}_{2}$ layer possesses many defect sites, which promote the migration of free electrons to the interface of amorphous and crystal phases. This work introduces a promising strategy to boost carrier transfer via building a holetransfer bridge and help us for designing more efficient photocatalysts.

\section{Supporting Information}

Supporting Information is available from the author. Experimental part. FTIR spectra, XRD, and $\mathrm{N}$ 1s XPS spectra of $\mathrm{TiO}_{2}, \mathrm{CN}-\mathrm{TiO}_{2}$ and $\mathrm{am} @ \mathrm{TiO}_{2}$ samples. TEM images of $\mathrm{TiO}_{2}$ precursor, $\mathrm{TiO}_{2}$-ref and $\mathrm{CN}-\mathrm{TiO}_{2}$ samples. Positron annihilation results of $\mathrm{TiO}_{2}, \mathrm{TiO}_{2}$-ref and 
am@ $\mathrm{TiO}_{2}$. Quasi in situ XPS measurement of $\mathrm{CN}-\mathrm{TiO}_{2}$-based samples. Raman, FTIR, Ti 2p3/2, O 1s XPS curves, ABPE and I-t results of $\mathrm{TiO}_{2}$-ref, am@ $\mathrm{TiO}_{2}$ and $\mathrm{IrO}_{\mathrm{x}}-\mathrm{am} @ \mathrm{TiO}_{2}$ samples. BET results. TEM images of $\mathrm{IrO}_{\mathrm{x}}-\mathrm{TiO}_{2}$-ref sample. Ir element line mapping result. Element mapping of reference $\mathrm{IrO}_{\mathrm{x}}-\mathrm{TiO}_{2}$-ref sample. The optical characteristics of the $\mathrm{TiO}_{2}$ ref, am@ $\mathrm{TiO}_{2}$ and $\mathrm{IrO}_{\mathrm{x}}-\mathrm{am} @ \mathrm{TiO}_{2}$. The online $\mathrm{GC}$ signals. $\mathrm{O}_{2}$ generation of the $\mathrm{am} @ \mathrm{TiO}_{2}$ and $\mathrm{TiO}_{2}$-ref samples. $\mathrm{O}_{2}$ generation rates of the $\mathrm{IrO}_{\mathrm{x}}-\mathrm{am} @ \mathrm{TiO}_{2}$ with the different $\mathrm{IrO}_{\mathrm{x}}$ content loading and the AQY plots. The photocatalytic water oxidation performance of samples of $\mathrm{IrO}_{\mathrm{x}}-\mathrm{TiO}_{2}$-ref, $\mathrm{IrO}_{\mathrm{x}}-\mathrm{am} @ \mathrm{TiO}_{2}-1$ and $\mathrm{IrO}_{\mathrm{x}}-\mathrm{am} @ \mathrm{TiO}_{2} \cdot \mathrm{O}_{2}$ generation values of the $\mathrm{TiO}_{2}$-ref. and am@ $\mathrm{TiO}_{2}$ samples under LED-405 and 425 illumination. The stability test of

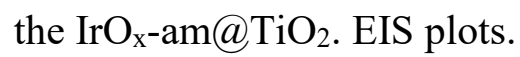

\section{Acknowledgements}

We acknowledge support from the National Key Research Program of China (2017YFA0204800, 2016YFA0202403), Natural Science Foundation of China (No. 21603136), the Changjiang Scholar and Innovative Research Team (IRT_14R33), the Fundamental Research Funds for the Central Universities (GK202003042). The 111 Project (B14041) and the Chinese National 1000-Talent-Plan program are also acknowledged.

\section{References}

(1) Zhang, P.; Wang, T.; Gong, J. Current mechanistic understanding of surface reactions over water-splitting photocatalysts. Chem 2018, 4, 223-245.

(2) Hisatomi, T.; Domen, K. Reaction systems for solar hydrogen production via water splitting with particulate semiconductor photocatalysts. Nat. Catal. 2019, 2, 387-399.

(3) Li, C.; Luo, Z.; Wang, T.; Gong, J. Surface, bulk, and interface: Rational design of hematite architecture toward efficient photo-electrochemical water splitting. Adv. Mater. 2018, 30,1707502 
(4) Wu, T.; Niu, P.; Yang, Y.; Yin, L.-C.; Tan, J.; Zhu, H.; Irvin, J. T. S.; Wang, L.; Liu, G.; Cheng, H.-M. Homogeneous doping of substitutional nitrogen/carbon in $\mathrm{TiO}_{2}$ plates for visible light photocatalytic water oxidation. Adv. Funct. Mater. 2019, 29, 1901943

(5) Li, P.; Kong, L.; Liu, J.; Yan, J.; Liu, S. Photoassisted hydrothermal synthesis of Irox$\mathrm{TiO}_{2}$ for enhanced water oxidation. ACS Sustainable Chem. Eng. 2019, 7, 17941-17949.

(6) Zhang, P.; Yu, L.; Lou, X. W. Construction of heterostructured $\mathrm{Fe}_{2} \mathrm{O}_{3}-\mathrm{TiO}_{2}$ microdumbbells for photoelectrochemical water oxidation. Angewandte Chemie-International Edition 2018, 57, 15076-15080.

(7) Miseki, Y.; Sayama, K. Photocatalytic water splitting for solar hydrogen production using the carbonate effect and the Z-scheme reaction. Adv. Energy Mater. 2019, 9, 1801294

(8) Sun, S.; Zhang, Y.-C.; Shen, G.; Wang, Y.; Liu, X.; Duan, Z.; Pan, L.; Zhang, X.; Zou, J.J. Photoinduced composite of $\mathrm{Pt}$ decorated $\mathrm{Ni}(\mathrm{OH})_{2}$ as strongly synergetic cocatalyst to boost $\mathrm{H}_{2} \mathrm{O}$ activation for photocatalytic overall water splitting. Appl. Catal. B-Environ. 2019, 243, 253-261.

(9) Badia-Bou, L.; Mas-Marza, E.; Rodenas, P.; Barea, E. M.; Fabregat-Santiago, F.; Gimenez, S.; Peris, E.; Bisquert, J. Water oxidation at hematite photoelectrodes with an iridium-based catalyst. J. Phys. Chem. C 2013, 117, 3826-3833.

(10) Ebina, Y.; Sakai, N.; Sasaki, T. Photocatalyst of lamellar aggregates of $\mathrm{RuO}_{\mathrm{x}}$-loaded perovskite nanosheets for overall water splitting. Phy. Chem. B 2005, 109, 17212-17216.

(11) Li, D.; Chen, R.; Wang, P.; Li, Z.; Zhu, J.; Fan, F.; Shi, J.; Li, C. Effect of facet-selective assembly of cocatalyst on $\mathrm{BiVO}_{4}$ photoanode for solar water oxidation. ChemCatChem 2019, 11, 3763-3769.

(12) Chen, S.; Takata, T.; Domen, K. Particulate photocatalysts for overall water splitting. Nat. Rev. Mater. 2017, 2, 17050

(13) Wang, Z.; Li, C.; Domen, K. Recent developments in heterogeneous photocatalysts for solar-driven overall water splitting. Chem. Soc. Rev. 2019, 48, 2109-2125.

(14) Fajrina, N.; Tahir, M. A critical review in strategies to improve photocatalytic water splitting towards hydrogen production. Int. J. Hydrogen Energy 2019, 44, 540-577.

(15) Kim, J. H.; Hansora, D.; Sharma, P.; Jang, J.-W.; Lee, J. S. Toward practical solar hydrogen production - an artificial photosynthetic leaf-to-farm challenge. Chem. Soc. Rev. 2019, 48, 1908-1971.

(16) Cai, J.; Shen, J.; Zhang, X.; Ng, Y. H.; Huang, J.; Guo, W.; Lin, C.; Lai, Y. Light-driven sustainable hydrogen production utilizing $\mathrm{TiO}_{2}$ nanostructures: A review. Small Methods 2019, 3, 1800184 
(17) Chen, M.; Liu, Y.; Li, C.; Li, A.; Chang, X.; Liu, W.; Sun, Y.; Wang, T.; Gong, J. Spatial control of cocatalysts and elimination of interfacial defects towards efficient and robust cigs photocathodes for solar water splitting. Energy Environ. Sci. 2018, 11, 2025-2034.

(18) Tada, H.; Mitsui, T.; Kiyonaga, T.; Akita, T.; Tanaka, K. All-solid-state Z-scheme in CdS-Au-TiO 2 three-component nanojunction system. Nat. Mater. 2006, 5, 782-786.

(19) Wang, C.; Zhao, Y.; Xu, H.; Li, Y.; Wei, Y.; Liu, J.; Zhao, Z. Efficient Z-scheme photocatalysts of ultrathin $\mathrm{g}-\mathrm{C}_{3} \mathrm{~N}_{4}$-wrapped $\mathrm{Au} / \mathrm{TiO}_{2}$-nanocrystals for enhanced visible-lightdriven conversion of $\mathrm{CO}_{2}$ with $\mathrm{H}_{2} \mathrm{O}$. Appl. Catal. B-Environ. 2020, 263, 118314

(20) Ye, F.; Su, Y.; Quan, X.; Chen, S.; Yu, H.; Li, H. Constructing desired interfacial energy band alignment of $\mathrm{Z}$-scheme $\mathrm{TiO}_{2}-\mathrm{Pd}-\mathrm{Cu}_{2} \mathrm{O}$ hybrid by controlling the contact facet for improved photocatalytic performance. Appl. Catal. B-Environ. 2019, 244, 347-355.

(21) Iwase, A.; Ng, Y. H.; Ishiguro, Y.; Kudo, A.; Amal, R. Reduced graphene oxide as a solid-state electron mediator in Z-scheme photocatalytic water splitting under visible light. $J$. Am. Chem. Soc. 2011, 133, 11054-11057.

(22) Jiang, Y.; Liao, J.-F.; Chen, H.-Y.; Zhang, H.-H.; Li, J.-Y.; Wang, X.-D.; Kuang, D.-B. All-solid-state $\mathrm{Z}$-scheme alpha- $\mathrm{Fe}_{2} \mathrm{O}_{3} /$ amine-rGo/ $\mathrm{CsPbBr}_{3}$ hybrids for visible-light-driven photocatalytic $\mathrm{CO}_{2}$ reduction. Chem 2020, 6, 766-780.

(23) He, H.; Cao, J.; Guo, M.; Lin, H.; Zhang, J.; Chen, Y.; Chen, S. Distinctive ternary $\mathrm{CdS} / \mathrm{Ni}_{2} \mathrm{P} / \mathrm{g}-\mathrm{C}_{3} \mathrm{~N}_{4}$ composite for overall water splitting: $\mathrm{Ni}_{2} \mathrm{P}$ accelerating separation of photocarriers. Appl. Catal. B-Environ. 2019, 249, 246-256.

(24) Ullattil, S. G.; Narendranath, S. B.; Pillai, S. C.; Periyat, P. Black $\mathrm{TiO}_{2}$ nanomaterials: A review of recent advances. Chem. Eng. J. 2018, 343, 708-736.

(25) Xu, F.; Zhang, L.; Cheng, B.; Yu, J. Direct z-scheme $\mathrm{TiO}_{2} / \mathrm{NiS}$ core-shell hybrid nanofibers with enhanced photocatalytic $\mathrm{H}_{2}$-production activity. ACS Sustainable Chem. Eng. 2018, 6, 12291-12298.

(26) Kong, L.; Ji, Y.; Dang, Z.; Yan, J.; Li, P.; Li, Y.; Liu, S. g-C $\mathrm{C}_{3} \mathrm{~N}_{4}$ loading black phosphorus quantum dot for efficient and stable photocatalytic $\mathrm{H}_{2}$ generation under visible light. Adv. Funct. Mater. 2018, 28, 1800668

(27) Zhou, X.; Qian, K.; Zhang, Y.; Li, D.; Wei, Z.; Wang, H.; Ye, R.; Liu, J.; Ye, B.; Huang, $\mathrm{W}$. Tuning the size of photo-deposited metal nanoparticles via manipulating surface defect structures of $\mathrm{TiO}_{2}$ nanocrystals. Chem. Commun. 2020, 56, 1964-1967.

(28) Guo, Y.; Chen, S.; Yu, Y.; Tian, H.; Zhao, Y.; Ren, J.-C.; Huang, C.; Bian, H.; Huang, M.; An, L.; Li, Y.; Zhang, R. Hydrogen-location-sensitive modulation of the redox reactivity for oxygen-deficient $\mathrm{TiO}_{2}$. J. Am. Chem. Soc. 2019, 141, 8407-8411. 
(29) Yan, J.; Wu, G.; Guan, N.; Li, L.; Li, Z.; Cao, X. Understanding the effect of surface/bulk defects on the photocatalytic activity of $\mathrm{TiO}_{2}$ : Anatase versus rutile. $P C C P$ 2013, 15, 10978-10988.

(30) Zhang, H.; Cai, J.; Wang, Y.; Wu, M.; Meng, M.; Tian, Y.; Li, X.; Zhang, J.; Zheng, L.; Jiang, Z.; Gong, J. Insights into the effects of surface/bulk defects on photocatalytic hydrogen evolution over $\mathrm{TiO}_{2}$ with exposed $\{001\}$ facets. Appl. Catal. B-Environ. 2018, 220, 126-136.

(31) Cheng, J.; Yang, J.; Kitano, S.; Juhasz, G.; Higashi, M.; Sadakiyo, M.; Kato, K.; Yoshioka, S.; Sugiyama, T.; Yamauchi, M.; Nakashima, N. Impact of Ir-valence control and surface nanostructure on oxygen evolution reaction over a highly efficient $\mathrm{Ir}-\mathrm{TiO}_{2}$ nanorod catalyst. ACS Catal. 2019, 9, 6974-6986.

(32) Oakton, E.; Lebedev, D.; Povia, M.; Abbott, D. F.; Fabbri, E.; Fedorov, A.; Nachtegaal, M.; Coperet, C.; Schmidt, T. J. $\mathrm{IrO}_{2}-\mathrm{TiO}_{2}$ : A high-surface-area, active, and stable electrocatalyst for the oxygen evolution reaction. ACS Catal. 2017, 7, 2346-2352.

(33) Naldoni, A.; Allieta, M.; Santangelo, S.; Marelli, M.; Fabbri, F.; Cappelli, S.; Bianchi, C. L.; Psaro, R.; Santo, V. D. Effect of nature and location of defects on bandgap narrowing in black $\mathrm{TiO}_{2}$ nanoparticles. J. Am. Chem. Soc. 2012, 134, 7600-7603.

(34) Frame, F. A.; Townsend, T. K.; Chamousis, R. L.; Sabio, E. M.; Dittrich, T.; Browning, N. D.; Osterloh, F. E. Photocatalytic water oxidation with nonsensitized $\mathrm{IrO}_{2}$ nanocrystals under visible and UVlight. J. Am. Chem. Soc. 2011, 133, 7264-7267.

(35) Zhao, Y.; Vargas-Barbosa, N. M.; Strayer, M. E.; McCool, N. S.; Pandelia, M.-E.; Saunders, T. P.; Swierk, J. R.; Callejas, J. F.; Jensen, L.; Mallouk, T. E. Understanding the effect of monomeric Iridium(III/IV) aquo complexes on the photoelectrochemistry of $\mathrm{IrO}_{\mathrm{x}} \cdot \mathrm{nH}_{2} \mathrm{O}$-catalyzed water-splitting systems. J. Am. Chem. Soc. 2015, 137, 8749-8757.

(36) Kan, M.; Qian, X.; Zhang, T.; Yue, D.; Zhao, Y. Highly active $\mathrm{IrO}_{\mathrm{x}}$ nanoparticles/black Si electrode for efficient water splitting with conformal $\mathrm{TiO}_{2}$ interface engineering. $A C S$ Sustainable Chem. Eng. 2017, 5, 10940-10946. 


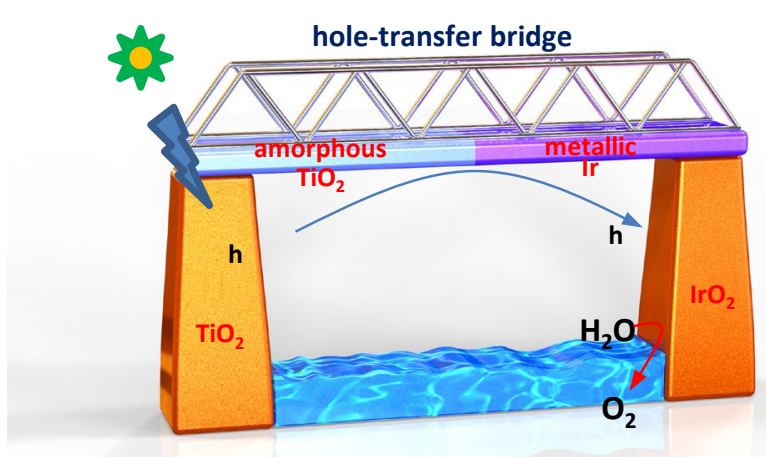

A hole-transfer bridge consisting of amorphous $\mathrm{TiO}_{2}$ and metallic $\mathrm{Ir}$ is designed for inducing the separation and migration of photogenerated carriers. With the help of surface $\mathrm{IrO}_{2}$ layer, the transferred holes are used timely for the reaction of water oxidation for $\mathrm{O}_{2}$ generation with the enhanced solar-to- $\mathrm{O}_{2}$ conversion efficiency even under visible-light illumination. 


\section{Supporting Information}

\section{Surface engineering to decrease the interface resistance for enhanced photocatalytic water oxidation}

Junqing Yan, ${ }^{\#}$ Jing Liu, , Yujin Ji, ${ }^{*}$ Munkhbayar Batmunkh, Dan Li, Xiaoshuang Liu, Xingzhong Cao, Youyong Li*, Shengzhong Liu*, and Tianyi Ma*

${ }^{\#}$ These authors contributed equally to this work.

${ }^{a}$ Key Laboratory of Applied Surface and Colloid Chemistry, Ministry of Education, Shaanxi Key Laboratory for Advanced Energy Devices, Shaanxi Engineering Lab for Advanced Energy Technology, School of Materials Science and Engineering, Shaanxi Normal University, Xi'an, 710119, People's Republic of China

E-mail: liusz@snnu.edu.cn

${ }^{b}$ Institute of Functional Nano \& Soft Materials (FUNSOM), Jiangsu Key Laboratory for Carbon-Based Functional Materials \& Devices, Soochow University, Suzhou, Jiangsu 215123, People's Republic of China

E-mail:yyli@suda.edu.cn

${ }^{c}$ Centre for Clean Environment and Energy, Griffith University, Gold Coast, Queensland 4222, Australia

${ }^{d}$ Discipline of Chemistry, School of Environmental and Life Sciences, Faculty of Science, University of Newcastle, Callaghan, NSW 2308, Australia

E-mail: tianyi.ma@newcastle.edu.au

${ }^{e}$ Positron Facility, Institute of High Energy Physics, Chinese Academy of Sciences, Beijing 100049, People's Republic of China 


\section{Experimental Procedures}

Materials. Chloroiridic acid $\left(\mathrm{H}_{2} \mathrm{IrCl}_{6}, \mathrm{AR}\right)$, ethanol (AR, 99.5\%), urea $\left(\mathrm{CH}_{4} \mathrm{~N}_{2} \mathrm{O}\right.$, AR) and silver nitrate $\left(\mathrm{AgNO}_{3}, \mathrm{AR}\right)$ were purchased from Sinopharm Chemical Reagent Company. Anatase titanium oxide $\left(\mathrm{TiO}_{2}, 99 \%\right)$ was bought from Beijing Innochem Science \& Technology Limited Company. Water was purified through Ulupure ultra-pure water system before utilization. All chemicals were utilized as received without further purification. Synthesis of am@TiO sample. The calculated urea and $\mathrm{TiO}_{2}$ (anatase phase) were transferred into one agate mortar for grinding thoroughly. The obtained mixture was added into one grinding miller for further treatment at the speed of 2000 revolutions per minute. Then the uniform product was moved into one tube furnace and treated at the temperature of $550{ }^{\circ} \mathrm{C} 4 \mathrm{~h}$ under $\mathrm{N}_{2}$ atmosphere. The heating rate was $2{ }^{\circ} \mathrm{C} / \mathrm{min}$. After finishing the calcination, the yellow product $\left(\mathrm{CN}-\mathrm{TiO}_{2}\right)$ was collected and grinded for further use. Some amount of $\mathrm{CN}-$ $\mathrm{TiO}_{2}$ was further added into the same tube furnace for treatment ca. $2 \mathrm{~h}$ under the $\mathrm{O}_{2}$ atmosphere. The reference $\mathrm{TiO}_{2}\left(\mathrm{TiO}_{2}\right.$-ref.) was synthesized by following the same above steps without the urea adding.

Synthesis of IrOx-am@TiO 2 . The nano-sized $\mathrm{IrO}_{\mathrm{x}}$ particles were loaded onto am@ $\mathrm{TiO}_{2}$ surface by the following steps: the calculated amount of am@ $@ \mathrm{TiO}_{2}$ was added into $\mathrm{H}_{2} \mathrm{IrCl}_{6}$ solution and then the mixture was treated by vacuum-pumping. After that, the suspension solution was treated further by the illumination of simulated sunlight $c a$. $4 \mathrm{~h}$. The black suspension was changed into colourless solution. The gray powder was collected by centrifugation and dried. And then the product was moved into the tube furnace for further treatment under the condition of $(5 \%) \mathrm{H}_{2} / \mathrm{Ar}$ and $200{ }^{\circ} \mathrm{C} 2 \mathrm{~h}$. Please note that the loading amount of $\mathrm{IrO}_{\mathrm{x}}$ is the theoretical mass ratio of metallic Ir being relative to $\mathrm{TiO}_{2}$.

Characterizations. X-ray diffraction (XRD) was measured by Rigaku Smartlab-9kW instrument using $\mathrm{Cu} \mathrm{K \alpha}$ X-ray $(\lambda=1.54186 \AA)$ radiation at a scanning rate of $2 \% \mathrm{~min}$. The morphology and energy-dispersive X-ray spectroscopy (EDS) mapping were characterized by 
FEI Tecnai G2 F20 transmission electron microscope (TEM) at an acceleration voltage of 200 $\mathrm{kV}$. The ultraviolet-visible-near infrared (UV-Vis-NIR) spectra in the air against $\mathrm{BaSO}_{4}$ was carried out on a Perkin-Elmer Lambd 1050 spectrophotometer. X-ray photoelectron spectroscopy (XPS) was carried out on a Kratos Axis Ultra DLD spectrometer with Al Ka (hv $=1486.6 \mathrm{eV}$ ) as the excitation source. Raman spectra was recorded on a in Via Reflex Raman Spectrophotometer. Room-temperature photoluminescence (PL) and time-resolved fluorescence spectroscopy were recorded on a PerkinElmer LS55 fluorescence spectrophotometer. Fourier transform infrared reflectance (FTIR) was carried out on a Bruker V70 spectrometer. Electrochemical measurements were conducted using a conventional three-electrode cell on a CHI760E (CH Instruments, Inc., Shanghai) electrochemical workstation. For the electrocatalytic measurements, the $\mathrm{TiO}_{2}$-based electrodes were prepared by following the steps: a $95 \mathrm{wt} . \%$ of the $\mathrm{TiO}_{2}$-based matrials $(3 \mathrm{mg})$, a drop of $5 \mathrm{wt} . \%$ of polytetrafluoroethylene and a few drops of ethanol were mixed and grinded to be a homogeneous white paste. Then the homogeneous white paste was embedded on ITO with a coating surface area of $1 \mathrm{~cm}^{2}(1 \mathrm{~cm} \times 1 \mathrm{~cm})$. The as-prepared electrodes were dried at $60{ }^{\circ} \mathrm{C}$ for $12 \mathrm{~h}$.

Photocatalytic water oxidation. Photocatalytic oxygen generation was performed in a vacuum system. Typically, catalyst sample of $100 \mathrm{mg}$ was suspended in $100 \mathrm{~mL} \mathrm{AgNO}_{3}$ $(0.01 \mathrm{~g} / \mathrm{mL})$ solution in the reaction cell. After evacuated for $30 \mathrm{~min}$, the reactor cell was irradiated by the lamps. The gaseous products were analyzed by an on-line gas chromatograph with thermal conductivity detector (Agilent GC-7890B; MS-5A column; Ar carrier; flow rate, $25 \mathrm{~mL} / \mathrm{min}$; the column temperature, $100{ }^{\circ} \mathrm{C}$ ). For the AQY calculation, the detail parameters of used LED lamps were measured by using AVANTES spectrometer (AvaSpecULS2048CL), the distance between the light source and reaction solution was kept to be 10 $\mathrm{cm}$, and the light spot radius was $c a .1 \mathrm{~cm}$, that is, the irradiation areas were all $3.14 \mathrm{~cm}^{2}$. The 
light intensity of the three LED lamps was kept the same to be $2.1232 \mathrm{~mW} / \mathrm{cm}^{2}$. The FWHM values of the LED-365, 405 and 425 were measured to be $10.02,11.75$ and $18.33 \mathrm{~nm}$, respectively.

Computational details. All density functional theory calculations was implemented in the Vienna Ab initio Simulation Package (VASP) with the projected-augmented wave pseudopotential (PAW) [S1-S2]. Then the PBE functional was adopted to describe the electronic exchange-correlation energy with the consideration of the van der Waals correction [S3]. The electronic cut-off energy was set to $500 \mathrm{eV}$ and the k-points were sampled at the Gamma point. The LDA+U method [S4] was chosen to consider the strong localized d electrons for Ti element and the screened effective electron-electron interaction parameter $U_{\text {eff }}$ was set to $5.8 \mathrm{eV}$ based on the previous reference [S5].
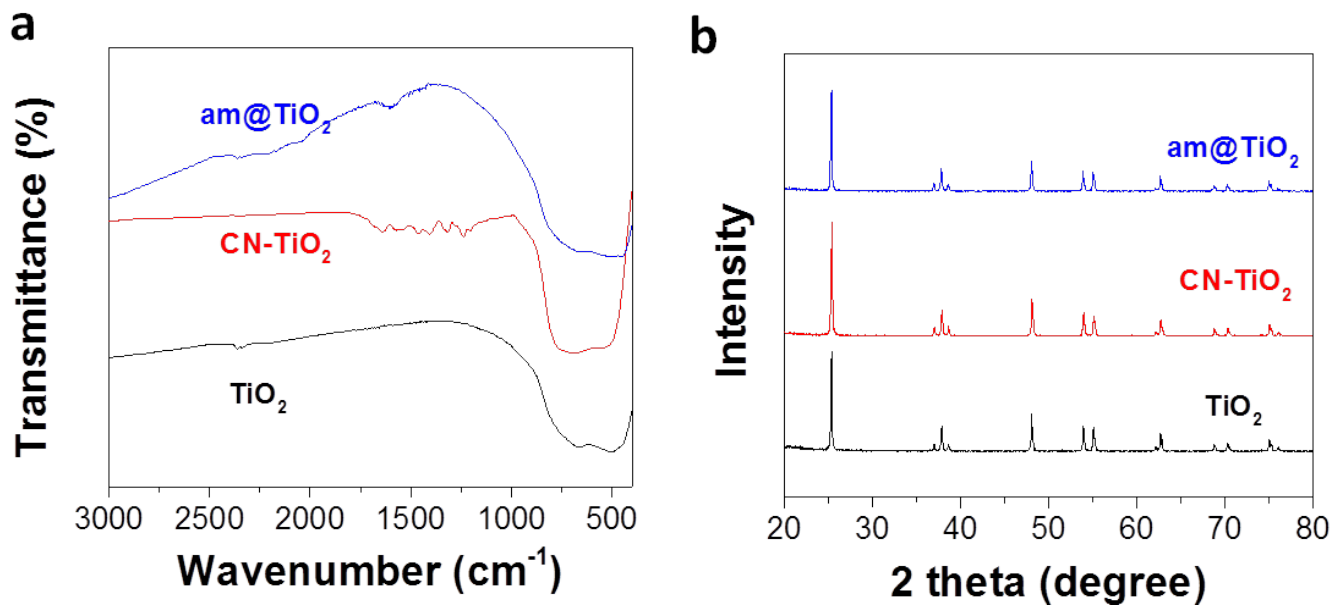

FigureS1. The structural information of the $\mathrm{TiO}_{2}, \mathrm{CN}-\mathrm{TiO}_{2}$ and $\mathrm{am} @ \mathrm{TiO}_{2}$ samples: (a) FTIR spectra and (b) XRD patterns. 


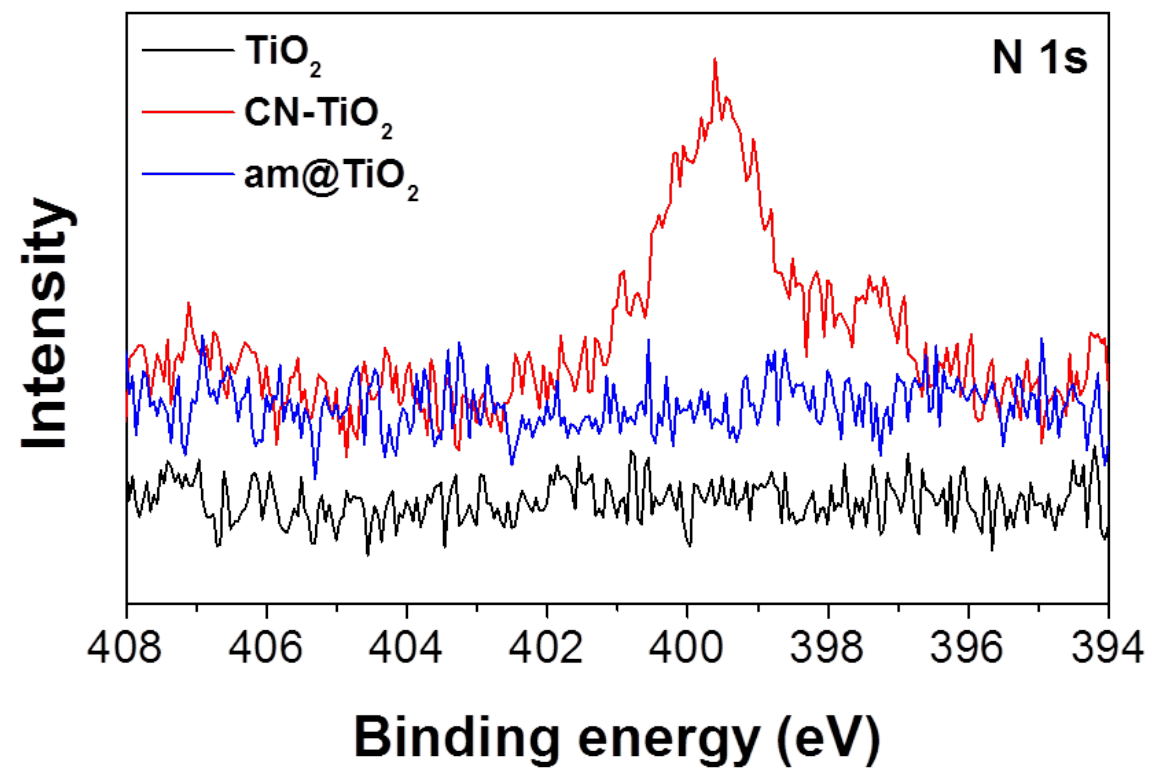

Figure S2. XPS N 1s spectra of the $\mathrm{TiO}_{2}, \mathrm{CN}-\mathrm{TiO}_{2}$ and $\mathrm{am} @ \mathrm{TiO}_{2}$ samples.
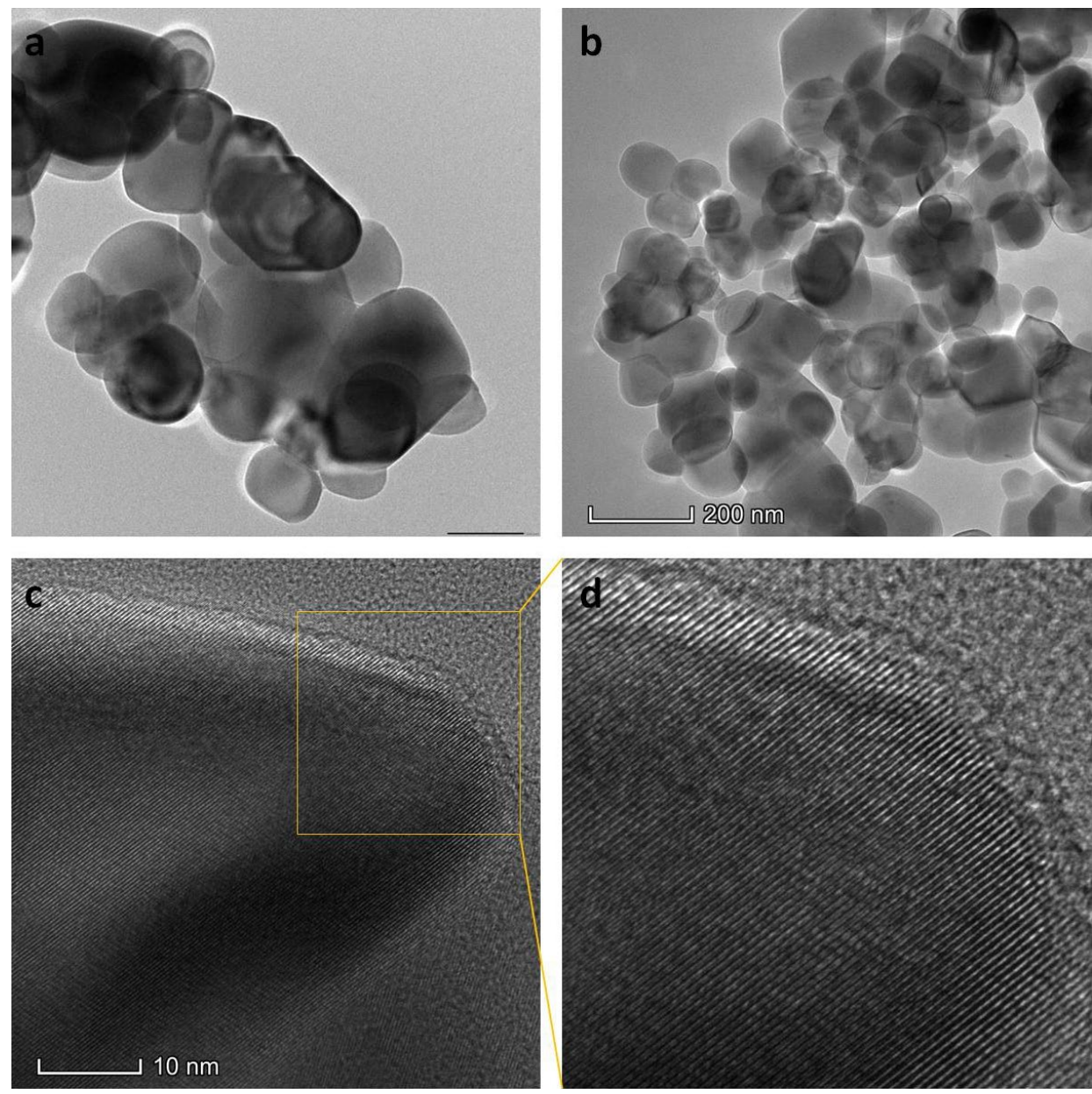

Figure S3. TEM images of the (a) $\mathrm{TiO}_{2}$ precursor, (b) $\mathrm{TiO}_{2}$-ref. (c and d) HRTEM of $\mathrm{TiO}_{2}$-ref. 

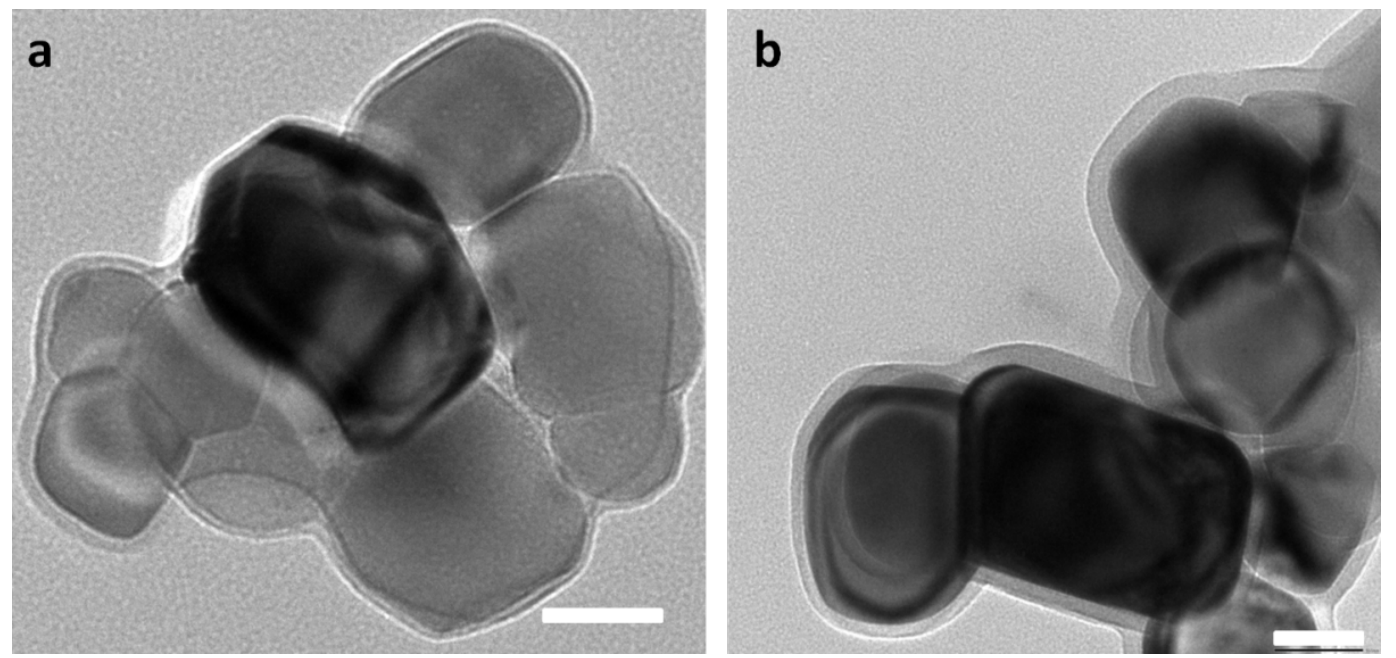

Figure S4. TEM images of the $\mathrm{CN}-\mathrm{TiO}_{2}$ with the different $\mathrm{CN}$ layer thickness, scale bar, 100 $\mathrm{nm}$. Please note that the two samples were synthesized from the mass ratios of $1: 1$ and 1:3 of $\mathrm{TiO}_{2}$ to urea.
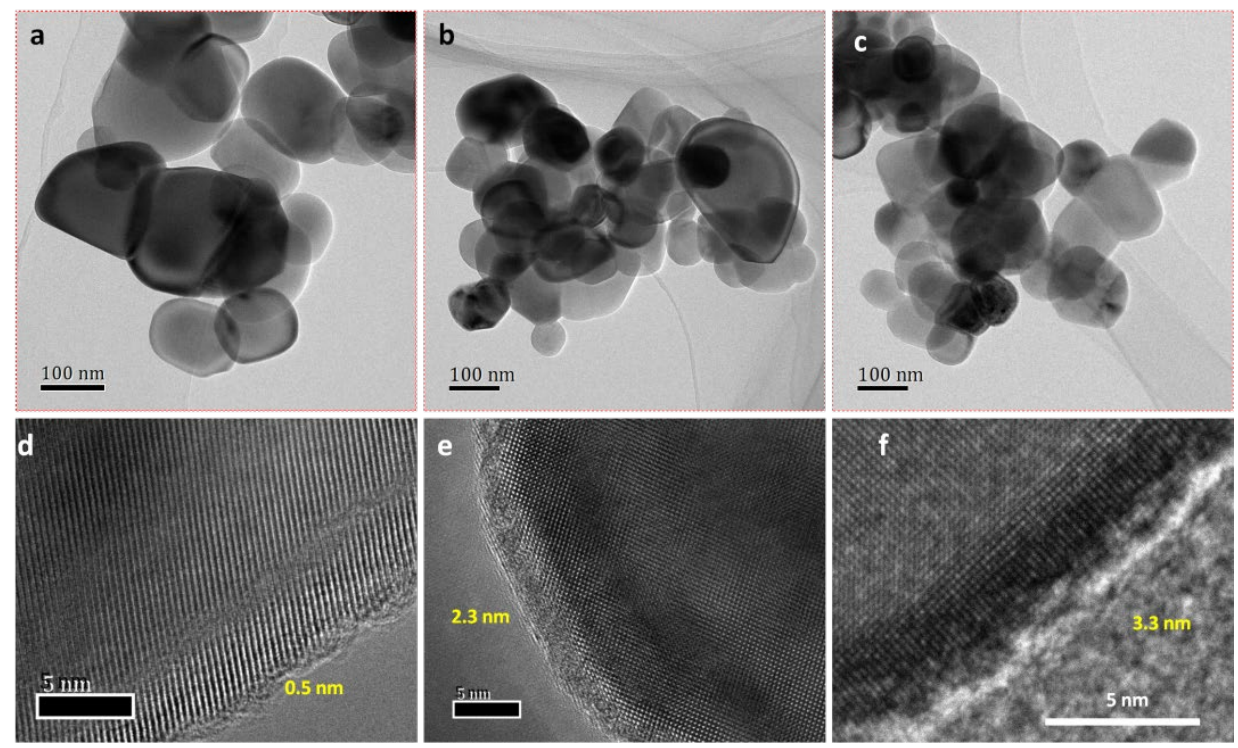

Figure S5. TEM and HRTEM images of the am@ $\mathrm{TiO}_{2}$ with different thicknesses of surface amorphous layer. (a)-(d), (b)-(e) and (c)-(f) are the one-to-one correspondence.

It should be noted that the three samples of a-c were synthesized from the calcination of $\mathrm{CN}$ $\mathrm{TiO}_{2}$ samples, which were obtained from the treatment of mixture of $\mathrm{TiO}_{2}$ and urea with the mass ratios of $1: 1,1: 2$ and $1: 3$. 
Table S1. Positron annihilation results of $\mathrm{TiO}_{2}, \mathrm{TiO}_{2}$-ref and am@ $\mathrm{TiO}_{2}$.

\begin{tabular}{|c|c|c|c|c|c|c|}
\hline Sample & $\tau_{1}(\mathrm{~ns})$ & $\mathrm{I}_{1}(\%)$ & $\tau_{2}(\mathrm{~ns})$ & $\mathrm{I}_{2}(\%)$ & $\tau_{3}(\mathrm{~ns})$ & $\mathrm{I}_{3}(\%)$ \\
\hline $\mathrm{TiO}_{2}$ & 0.1749 & 37.1 & 0.3528 & 61.3 & 2.266 & 1.609 \\
\hline $\mathrm{TiO}_{2}$-ref & 0.1737 & 41.75 & 0.3575 & 56.64 & 2.366 & 1.610 \\
\hline $\mathrm{am} @ \mathrm{TiO}_{2}$ & 0.1764 & 39.1 & 0.3726 & 59.4 & 2.424 & 1.563 \\
\hline
\end{tabular}

a

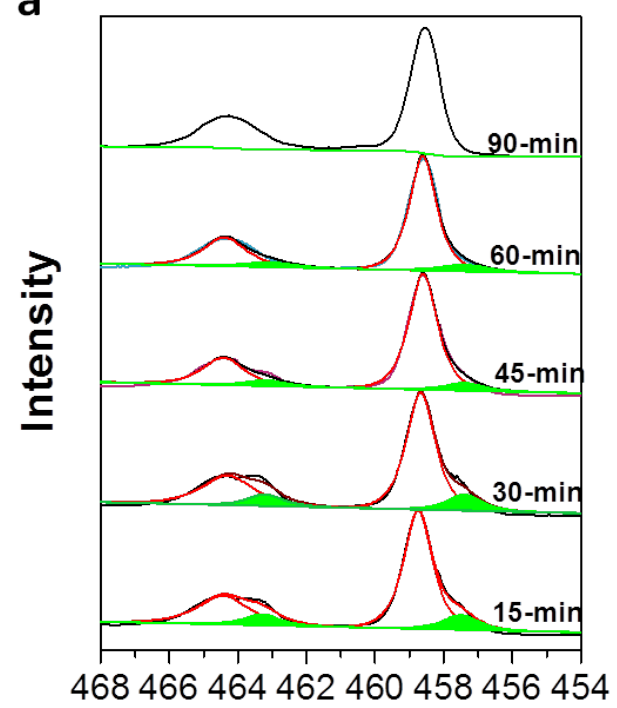

Binding energy (eV) b

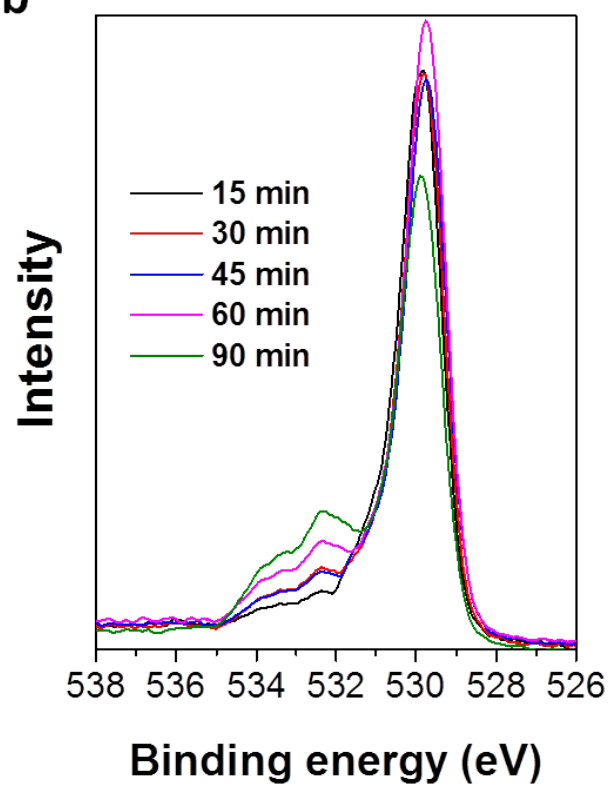

Figure S6. Quasi in situ XPS measurement of $\mathrm{CN}-\mathrm{TiO}_{2}$-based samples, obtained from the calcination of $\mathrm{CN}-\mathrm{TiO}_{2}$ sample at $500^{\circ} \mathrm{C}$ with the different time, $15 \mathrm{~min}, 30 \mathrm{~min}, 45 \mathrm{~min}, 60$ min and 90 min. (a) Ti 2p XPS and (b) O 1s XPS spectra. 
a

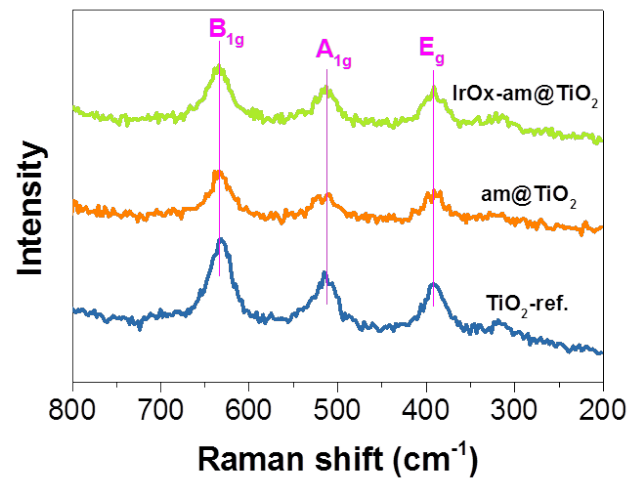

b

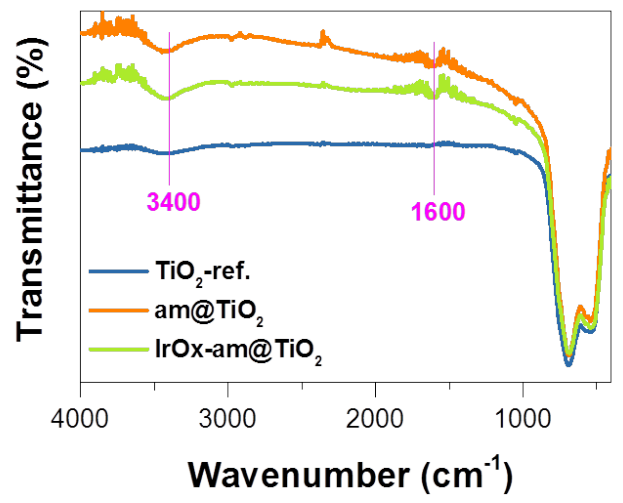

Figure S7. Structure information of the $\mathrm{TiO}_{2}$-ref, am@ $\mathrm{TiO}_{2}$ and $\mathrm{IrO}_{\mathrm{x}}-\mathrm{am} @ \mathrm{TiO}_{2}$ : (a) Raman and (b) FTIR spectra.
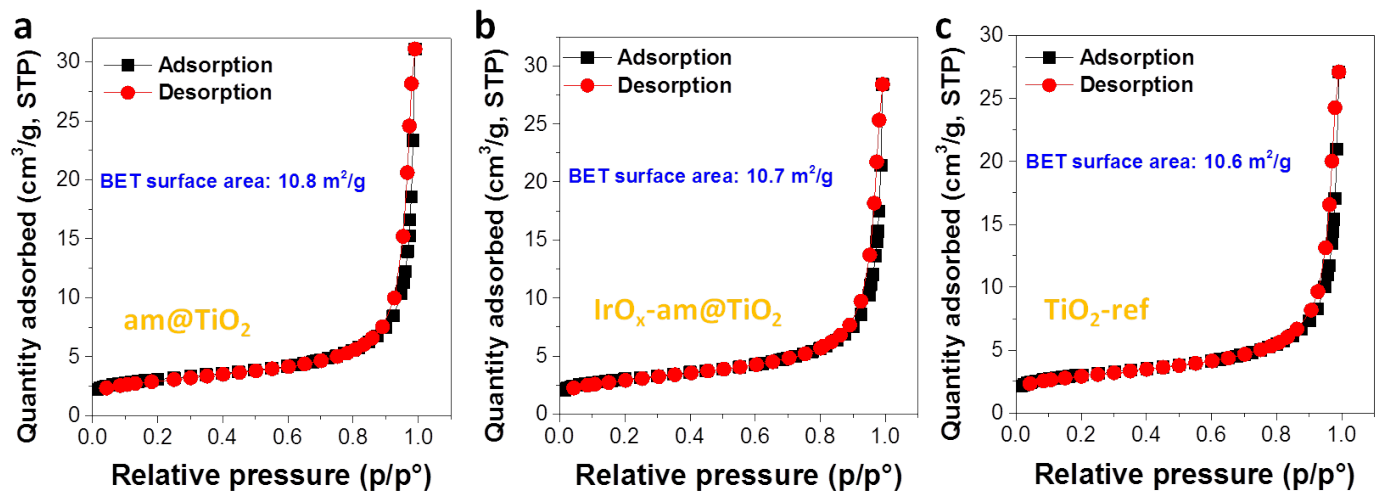

Figure S8. The $\mathrm{N}_{2}$ adsorption and desorption plots and the corresponding BET surface areas of the am@ $\mathrm{TiO}_{2}, \mathrm{IrO}_{\mathrm{x}}-\mathrm{am} @ \mathrm{TiO}_{2}$ and $\mathrm{TiO}_{2}$-ref samples.
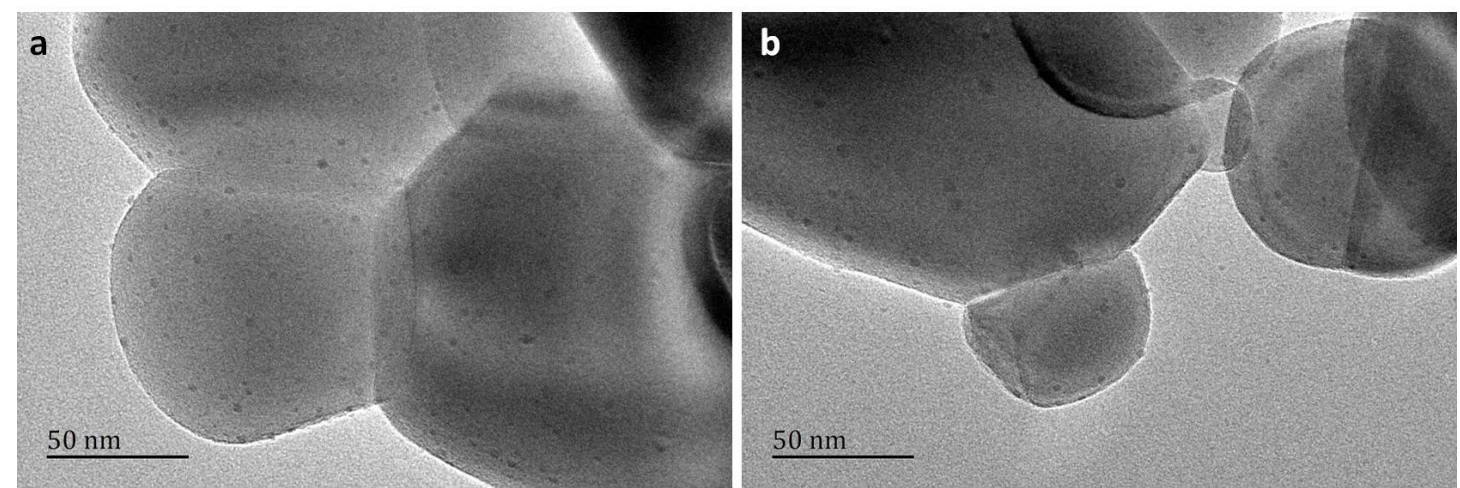

Figure S9. TEM images of $\mathrm{IrO}_{\mathrm{x}}-\mathrm{am} @ \mathrm{TiO}_{2}$ sample. 

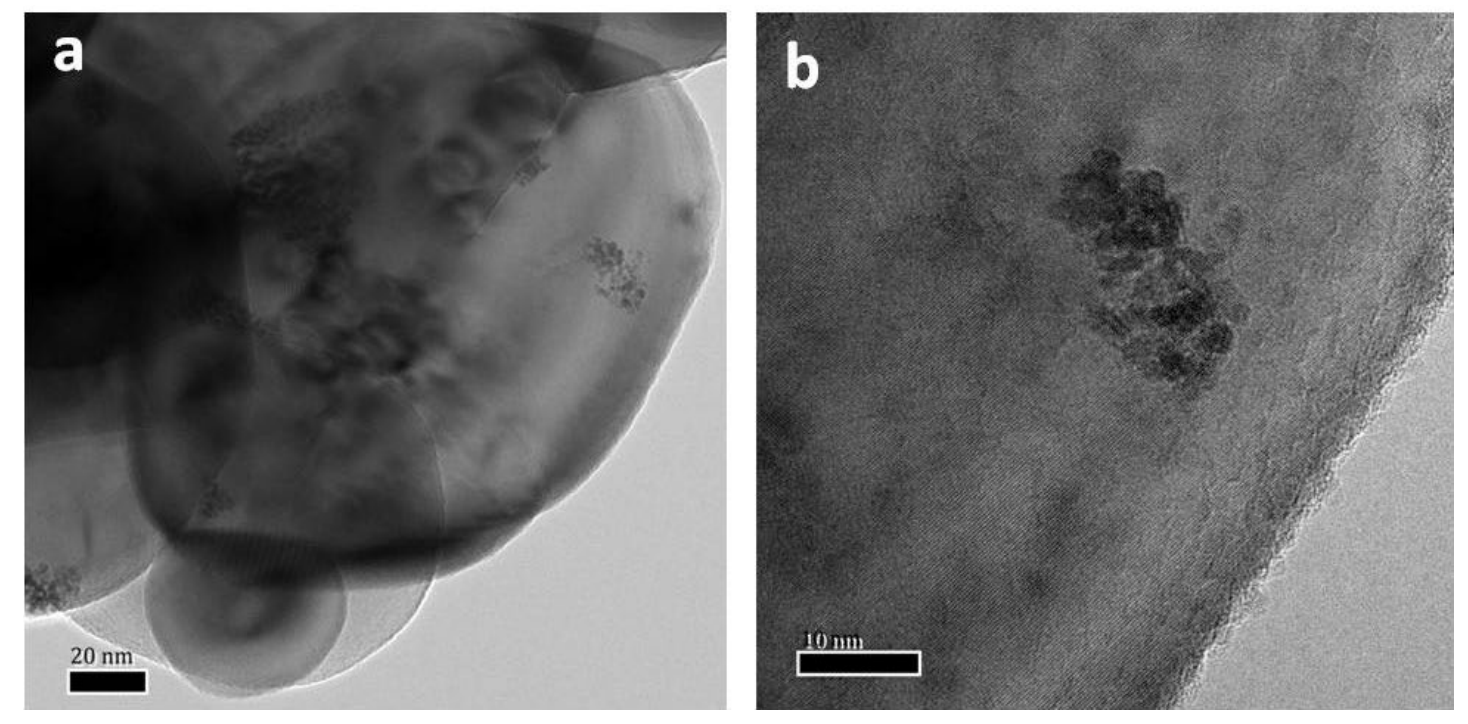

Figure S10. (a) TEM and (b) HRTEM image of $\mathrm{IrO}_{\mathrm{x}}-\mathrm{TiO}_{2}$-ref sample.

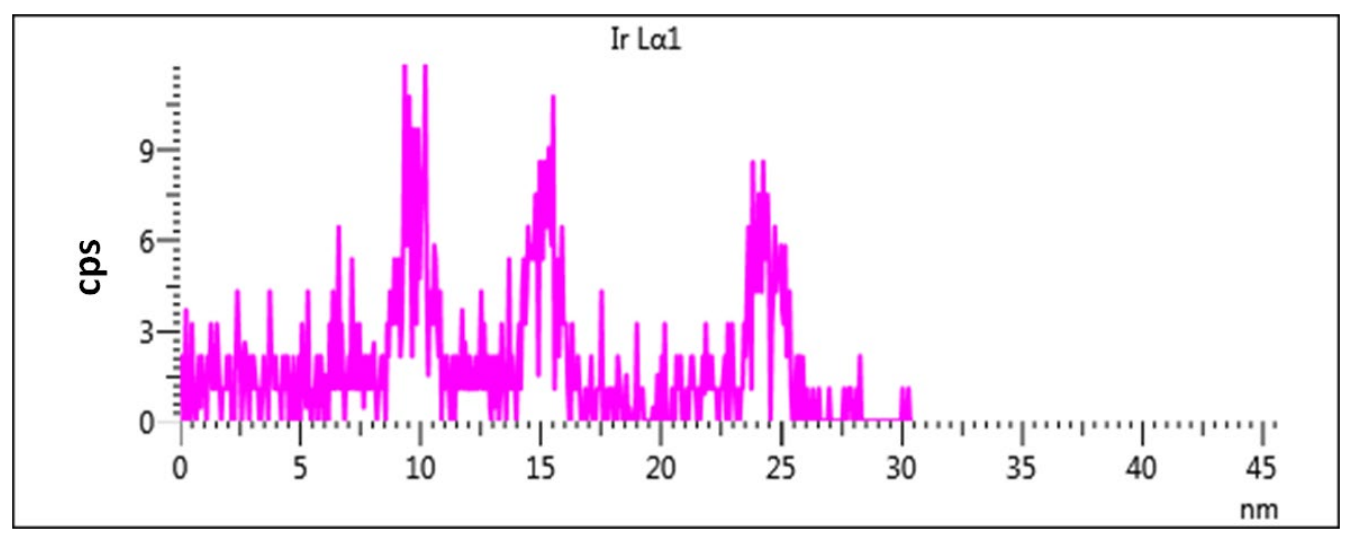

Figure S11. The corresponding line mapping result of Ir element of $\mathrm{IrO}_{\mathrm{x}}-\mathrm{am} @ \mathrm{TiO}_{2}$ sample. 

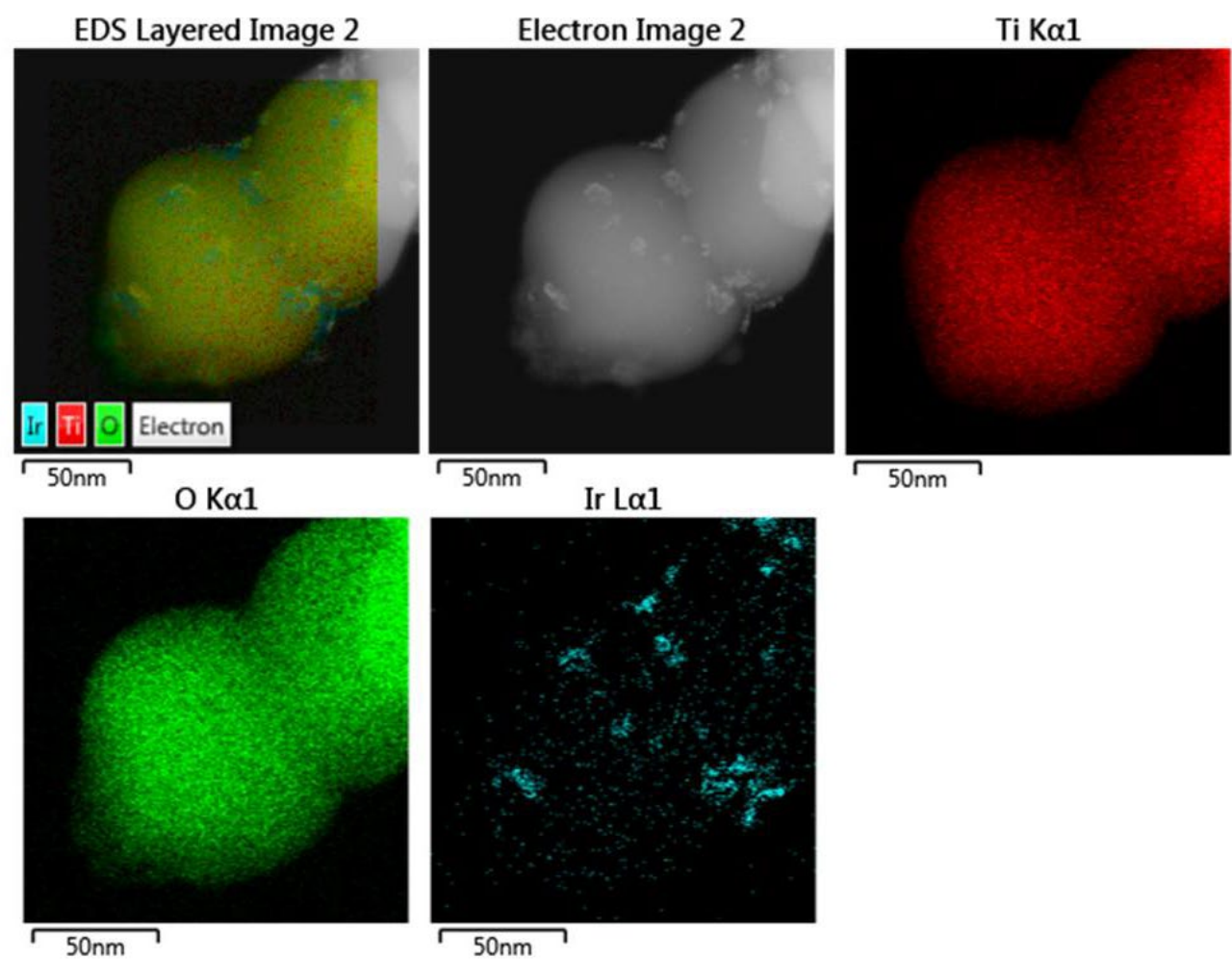

Figure S12. Element mapping of reference $\mathrm{IrO}_{\mathrm{x}}-\mathrm{TiO}_{2}$-ref sample without amorphous $\mathrm{TiO}_{\mathrm{x}}$ layer.
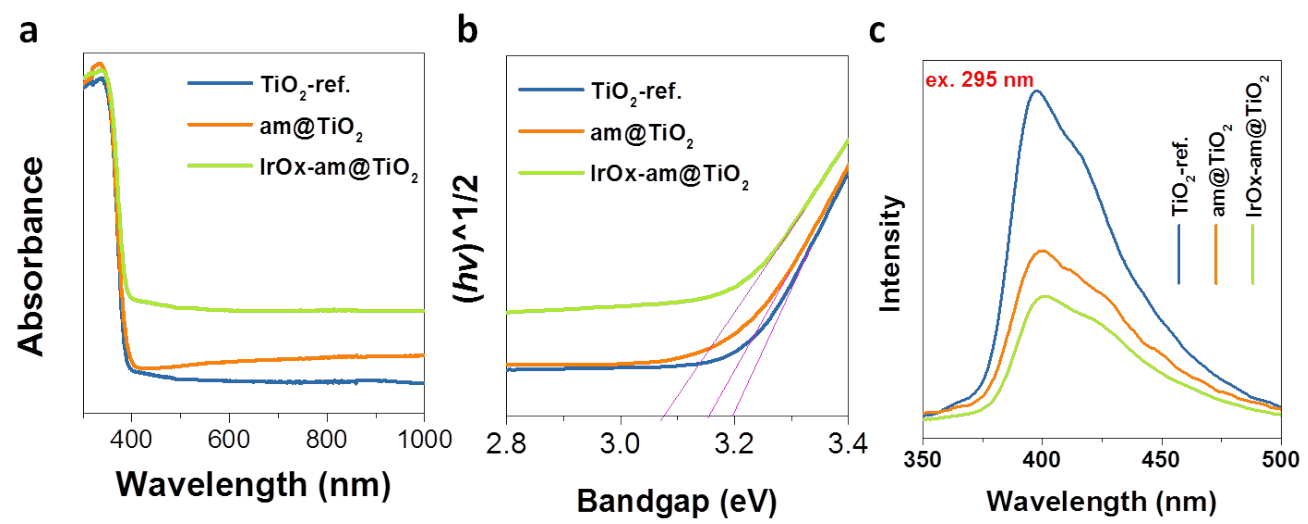

Figure S13. The optical characteristics of the $\mathrm{TiO}_{2}-\mathrm{ref}, \mathrm{am} @ \mathrm{TiO}_{2}$ and $\mathrm{IrO}_{\mathrm{x}}-\mathrm{am} @ \mathrm{TiO}_{2}$ : (a)

UV-Vis-NIR absorption spectra, (b) band gap calculations and (c) room-temperature PL spectra under the excitation wavelength of $295 \mathrm{~nm}$. 


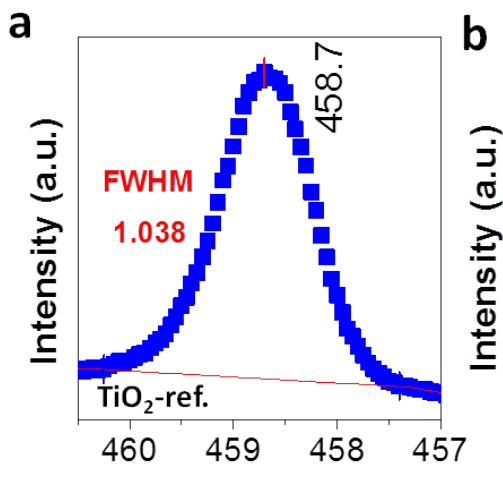

Binding energy (eV)
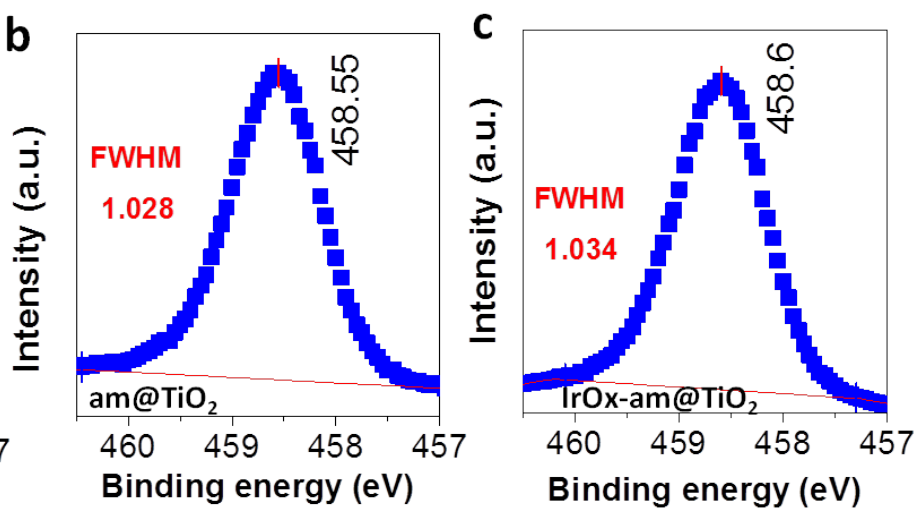

Figure S14. Ti 2p $\mathrm{p}_{3 / 2}$ XPS curves of the $\mathrm{TiO}_{2}$-ref, am@ $\mathrm{TiO}_{2}$ and $\mathrm{IrO}_{\mathrm{x}}-\mathrm{am} @ \mathrm{TiO}_{2}$. The fitted FWHM and the peak location values are shown. Please note that the FWHM values are obtained from fitting and only for the purpose of offering the qualitative description of the symmetry of Ti $2 \mathrm{p}_{3 / 2}$ peak

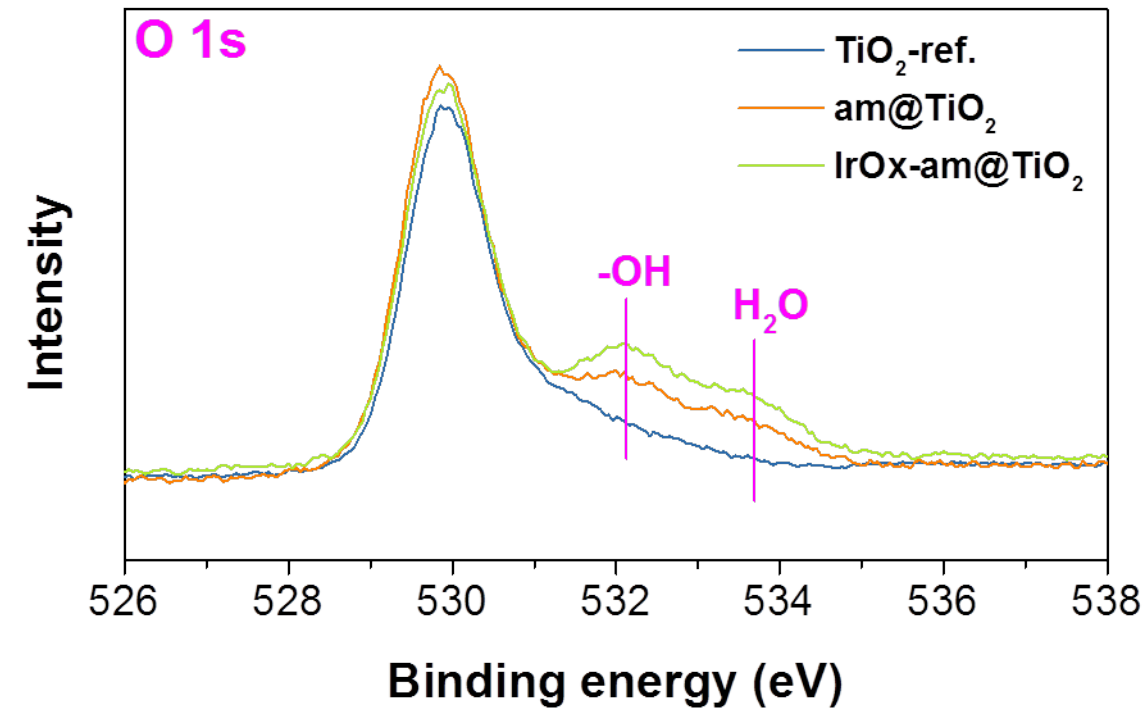

Figure S15. O 1s XPS spectra of the $\mathrm{TiO}_{2}$-ref, am@ $\mathrm{TiO}_{2}$ and $\mathrm{IrO}_{\mathrm{x}}-\mathrm{am} @ \mathrm{TiO}_{2}$. 

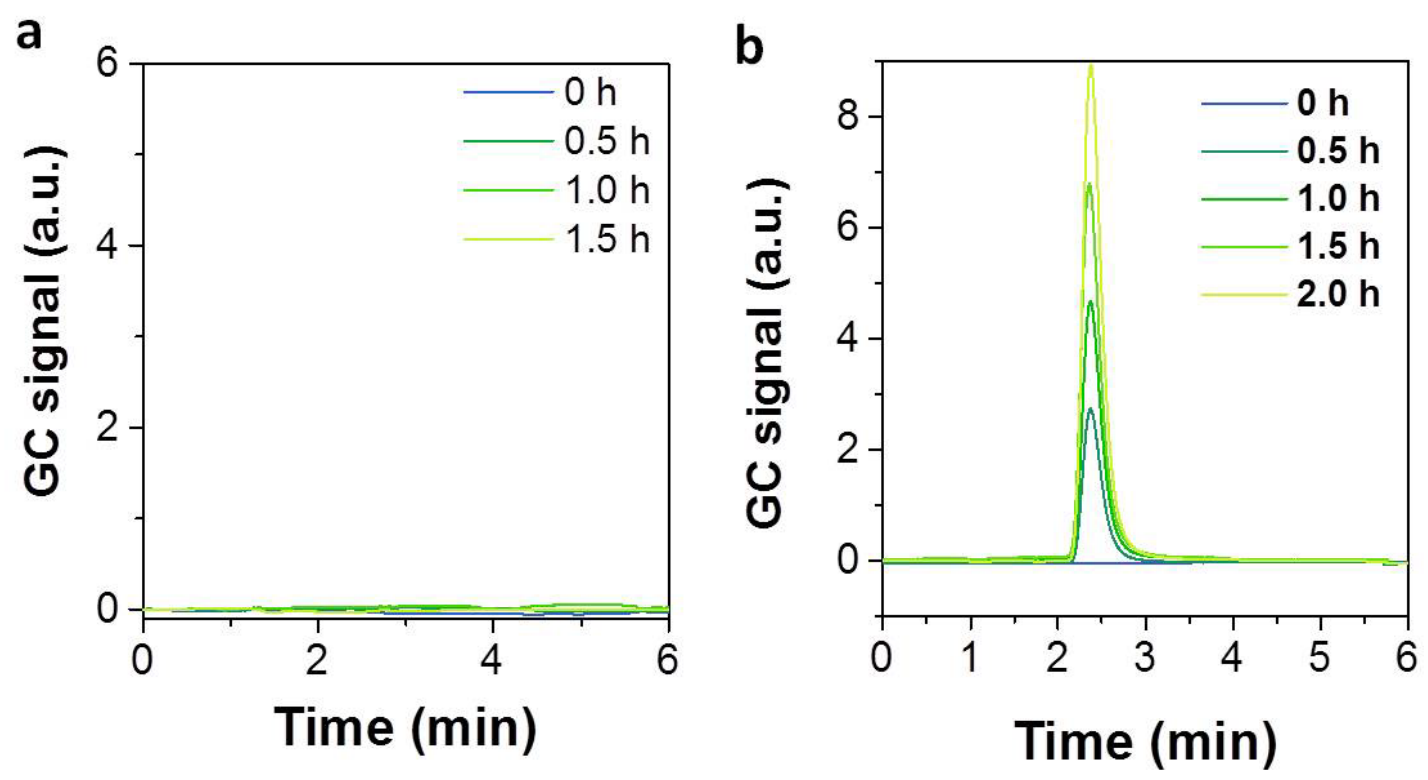

Figure S16. The online GC signals of the $\mathrm{IrO}_{\mathrm{x}}-\mathrm{am} @ \mathrm{TiO}_{2}$ (a) without and (b) with simulated sunlight illumination (AM 1.5).

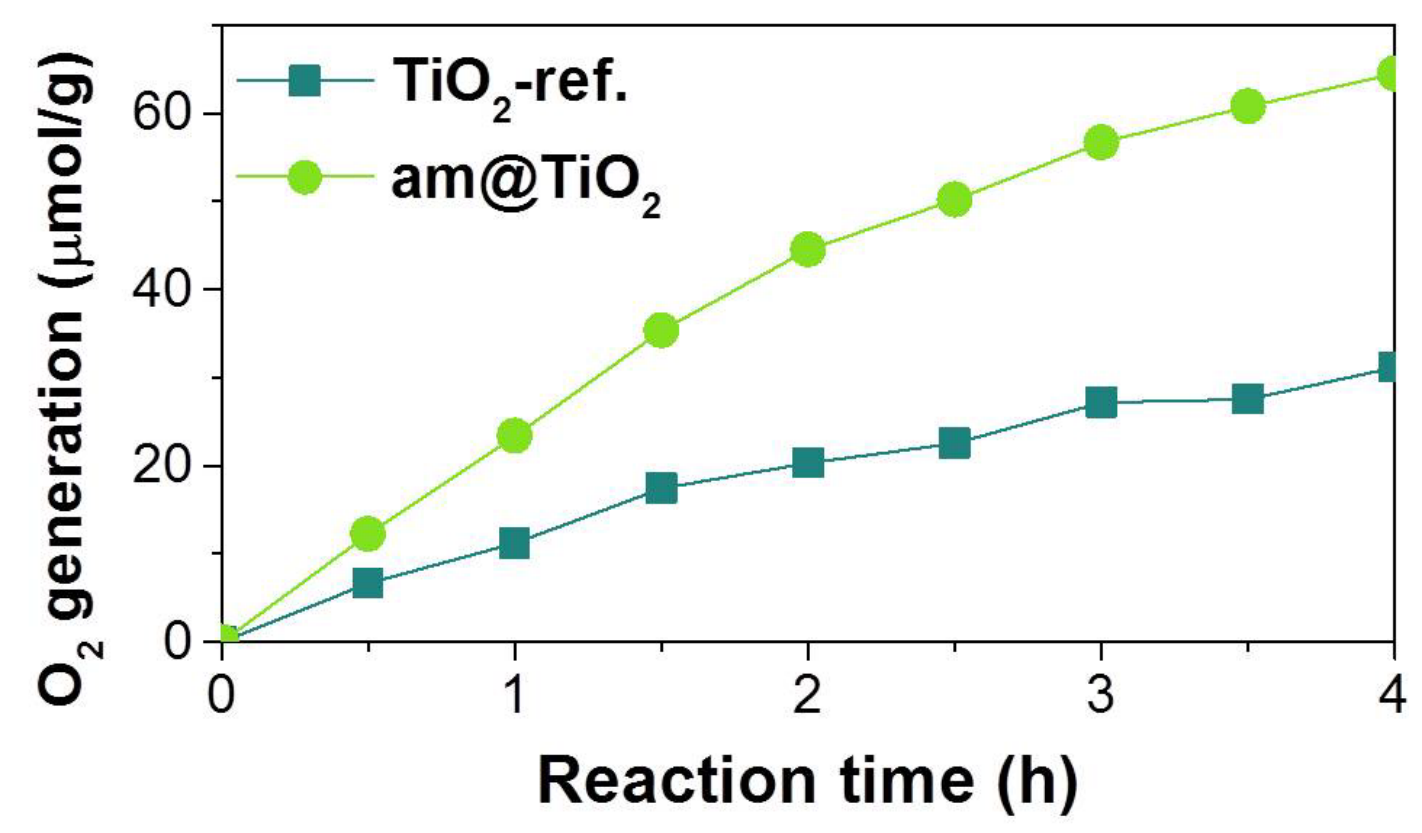

Figure S17. $\mathrm{O}_{2}$ generation of the $\mathrm{am} @ \mathrm{TiO}_{2}$ and $\mathrm{TiO}_{2}$-ref samples under the simulated sunlight illumination. 
a

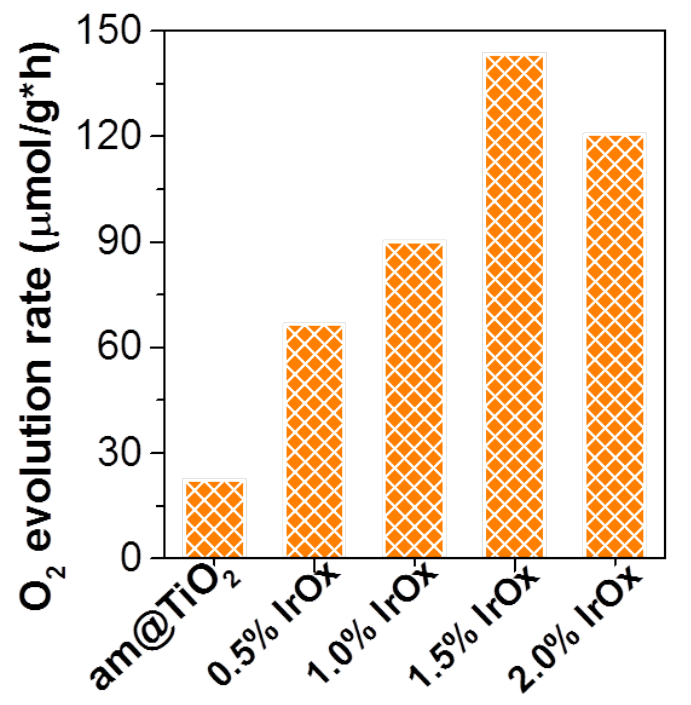

b

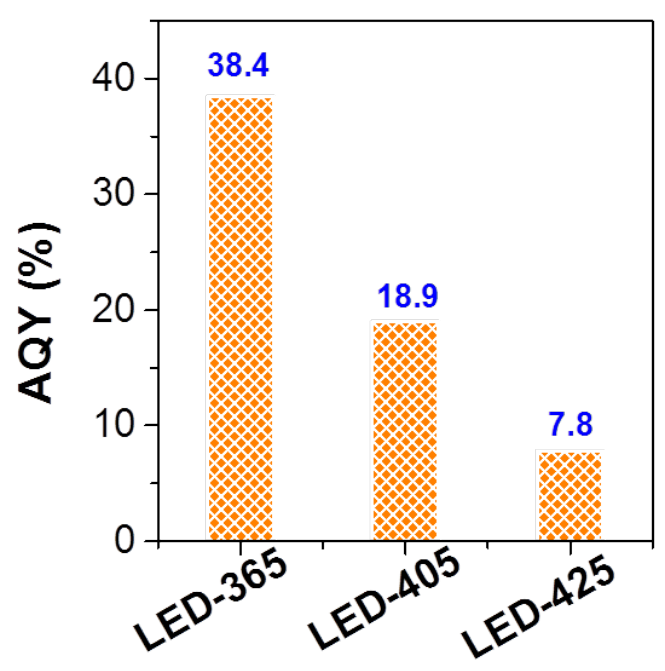

Figure S18. (a) $\mathrm{O}_{2}$ generation rates measured under the illumination of simulated sunlight of the $\mathrm{IrO}_{\mathrm{x}}$-am $@ \mathrm{TiO}_{2}$ with the different $\mathrm{IrO}_{\mathrm{x}}$ content loading. (b) AQY values of $1.5 \% \mathrm{IrO}_{\mathrm{x}}-$ am@ $\mathrm{TiO}_{2}$ sample measured under the illumination of LED-365, LED-405 and LED-425.

a

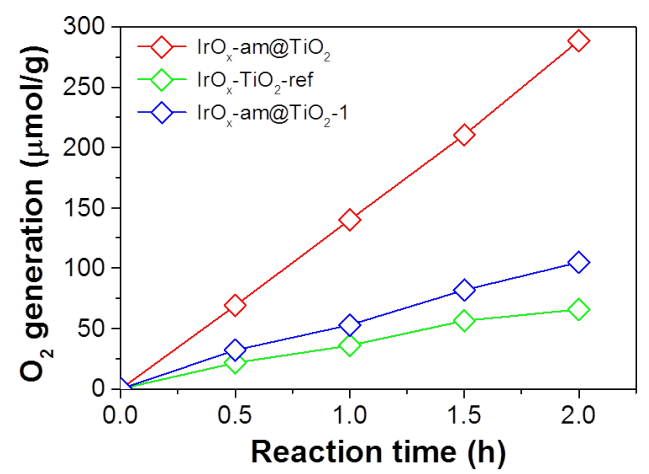

b

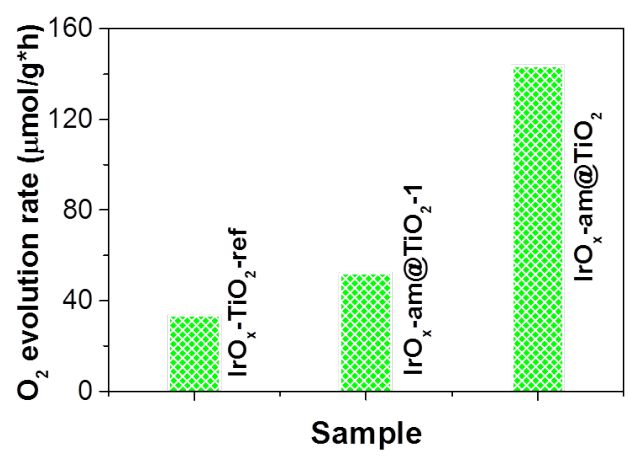

Figure S19. The photocatalytic water oxidation performance of samples of $\mathrm{IrO}_{\mathrm{x}}-\mathrm{TiO}_{2}-\mathrm{ref}$, $\mathrm{IrO}_{\mathrm{x}}-\mathrm{am} @ \mathrm{TiO}_{2}-1$ and $\mathrm{IrO}_{\mathrm{x}}-\mathrm{am} @ \mathrm{TiO}_{2}$. (a) The real-time oxygen production and (b) the corresponding $\mathrm{O}_{2}$ generation rate. Please note that the sample of $\mathrm{IrO}_{\mathbf{x}}-\mathrm{TiO}_{2}$-ref was synthesized by using the same way with $\mathrm{IrO}_{\mathrm{x}}-\mathrm{am} @ \mathrm{TiO}_{2}$ except using the $\mathrm{TiO}_{2}$-ref. And the reference sample of $\mathrm{IrO}_{\mathrm{x}}$-am $@ \mathrm{TiO}_{2}-1$ was obtained from the similar preparation process with $\mathrm{IrO}_{\mathrm{x}}$-am@ $\mathrm{TiO}_{2}$ but using the $\mathrm{N}_{2}$. 
a

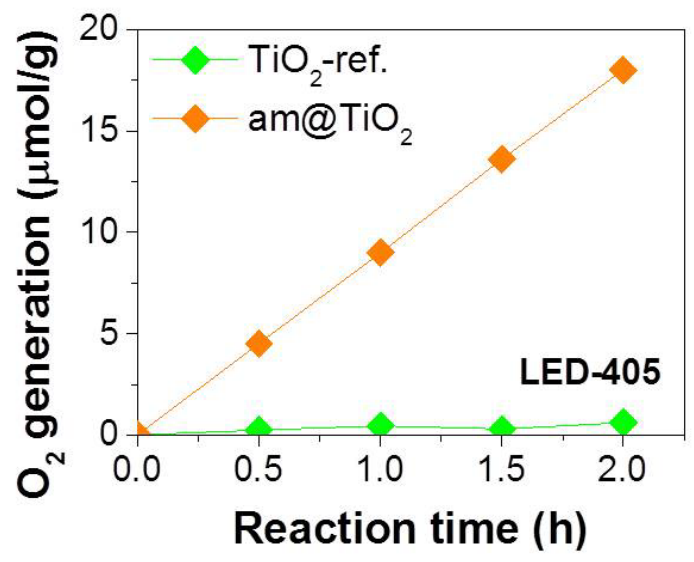

b

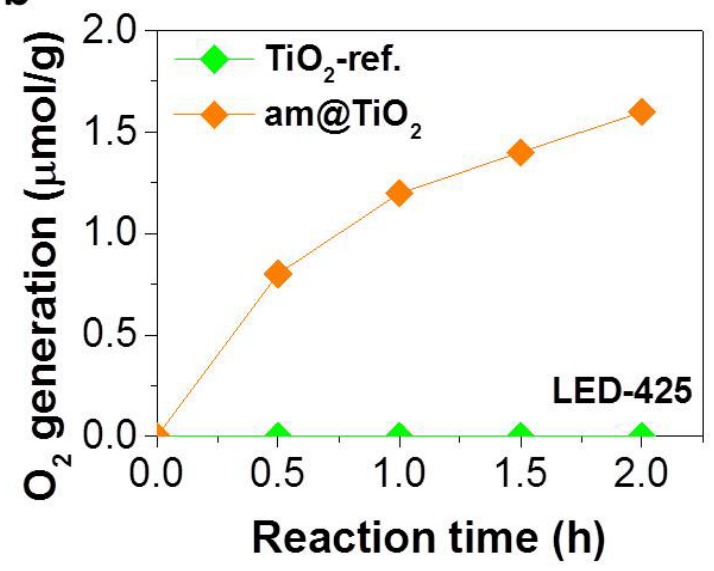

Figure S20. $\mathrm{O}_{2}$ generation values of the $\mathrm{TiO}_{2}$-ref. and $\mathrm{am} @ \mathrm{TiO}_{2}$ samples under LED-405 and 425 illumination.

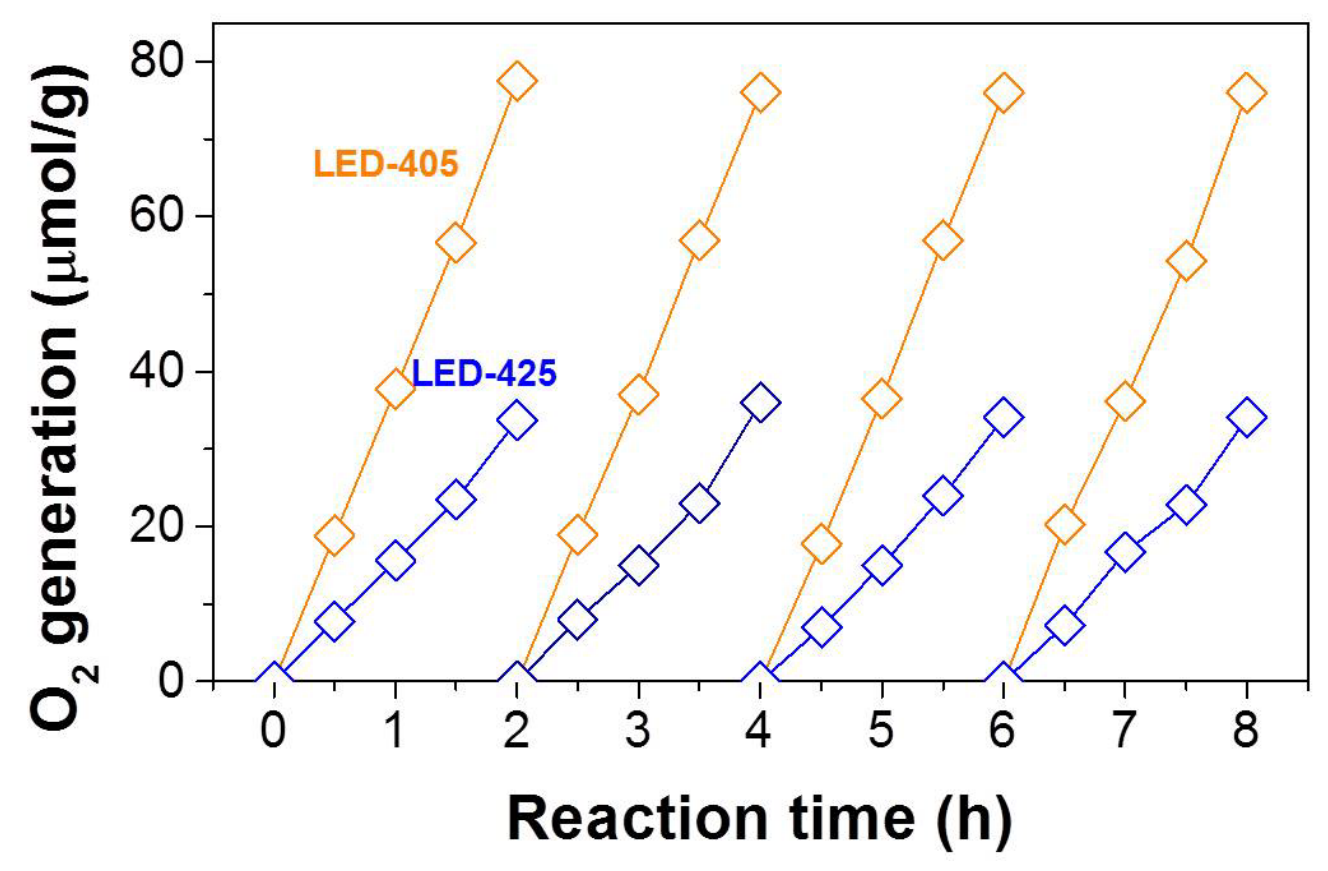

Figure S21. The stability test of the $\mathrm{IrO}_{\mathrm{x}}-\mathrm{am} @ \mathrm{TiO}_{2}$. Please note that the sample was recycled after the reaction of $2 \mathrm{~h}$ and treated by stirring in $0.01 \mathrm{M} \mathrm{HNO}_{3}$ ca. $1 \mathrm{~h}$ to remove the surface loading Ag particles, then added into the reaction solution for the next cycle measurement. 
Table S2. Integral area values calculated from the O 1s XPS spectra of the $\mathrm{IrO}_{\mathrm{x}}-\mathrm{am} @ \mathrm{TiO}_{2}$.

\begin{tabular}{lll}
\hline & Before stability & After stability \\
O-Ti & 2.475 & 2.471 \\
-OH group & 0.813 & 1.023 \\
Adsorbed $\mathrm{H}_{2} \mathrm{O}$ & 0.595 & 0.725 \\
\hline
\end{tabular}
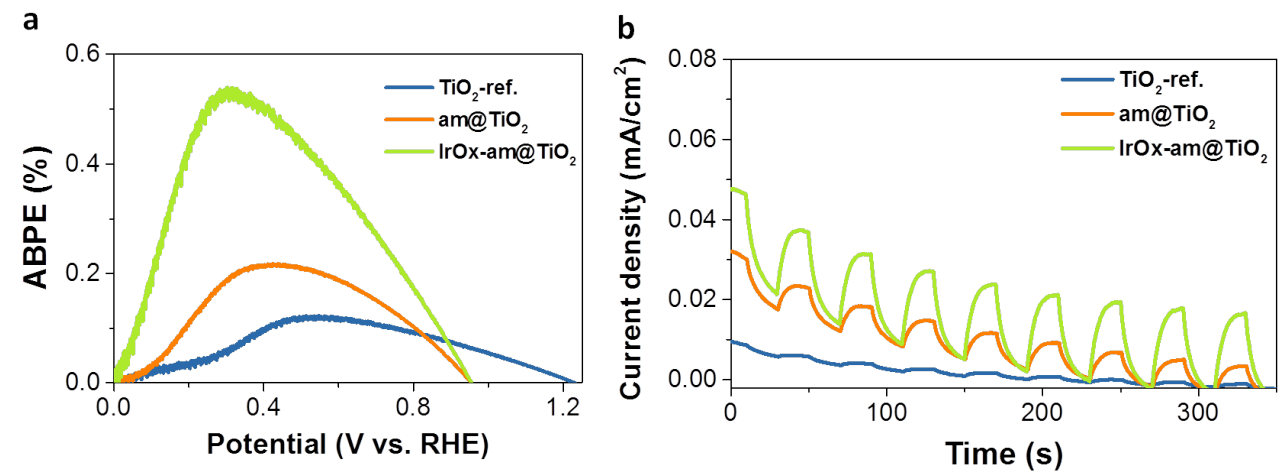

Figure S22. (a) ABPE curves of the $\mathrm{TiO}_{2}$-ref, am@ $\mathrm{TiO}_{2}$ and $\mathrm{IrO} \mathrm{x}_{\mathrm{x}}-\mathrm{am} @ \mathrm{TiO}_{2}$. (b) The currenttime response of these three samples measured under the illumination of LED-425 lamp.
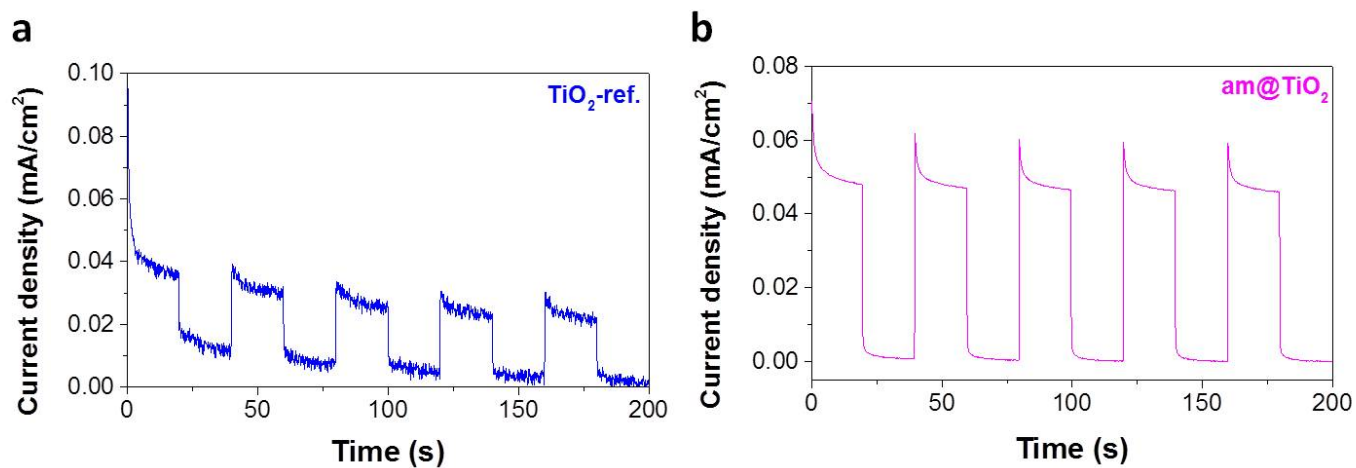

Figure S23. I-t responses of (a) $\mathrm{TiO}_{2}$-ref and (b) am@ $\mathrm{TiO}_{2}$ samples. 


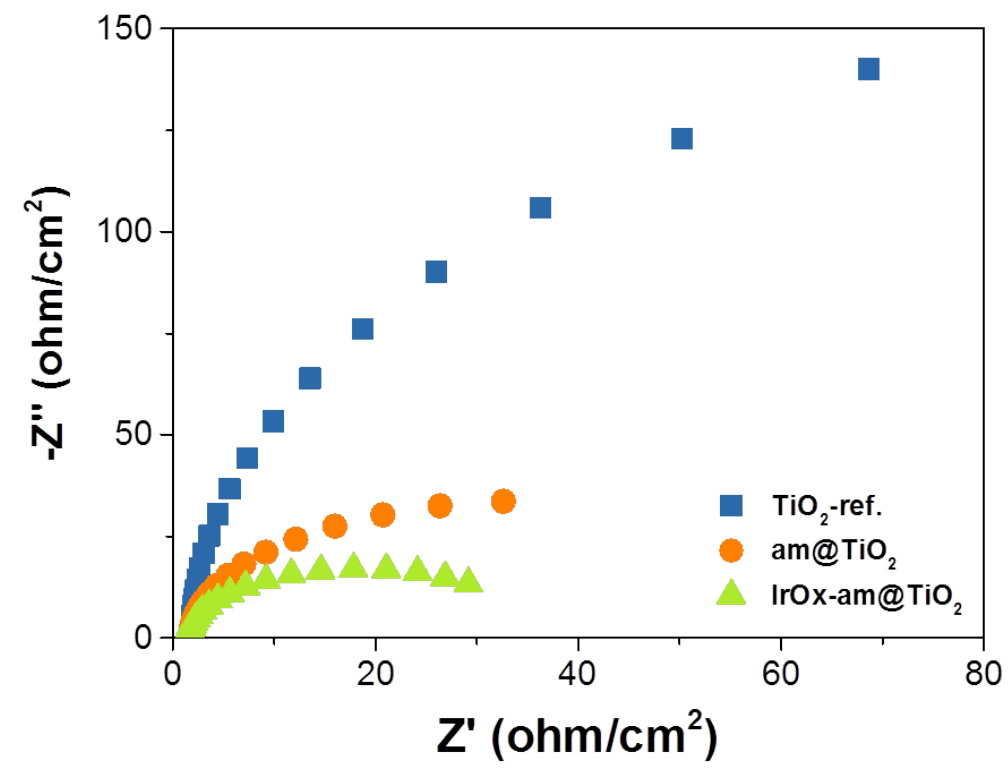

Figure S24. EIS plots of the samples measured in dark condition.

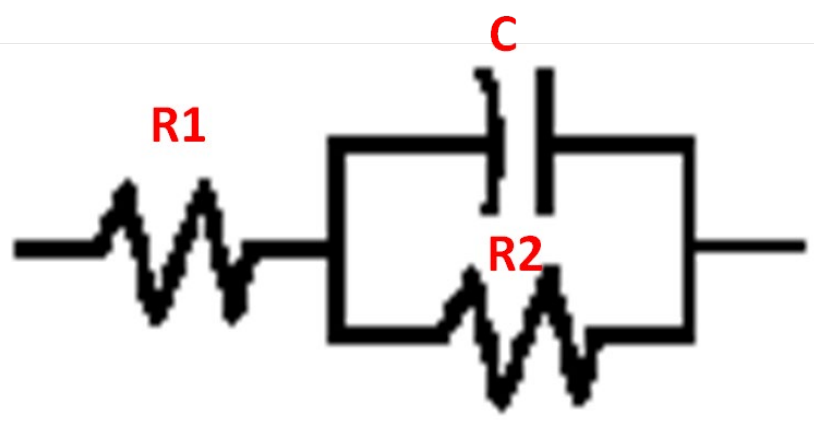

Figure S25. A circuit diagram used for the EIS study.

Table S3. The fitted results of the EIS plots for the $\mathrm{TiO}_{2}$-ref, am@ $\mathrm{TiO}_{2}$ and $\mathrm{IrO}_{\mathrm{x}}-\mathrm{am} @ \mathrm{TiO}_{2}$ samples

\begin{tabular}{|c|c|c|c|c|}
\hline \multirow{2}{*}{ Sample } & \multicolumn{2}{|c|}{ Dark } & \multicolumn{2}{c|}{ Illumination } \\
\cline { 2 - 5 } & $\mathrm{R} 1$ & $\mathrm{R} 2$ & $\mathrm{R} 1\left(\mathrm{ohm} / \mathrm{cm}^{2}\right)$ & $\mathrm{R} 2$ \\
& $\left(\mathrm{ohm} / \mathrm{cm}^{2}\right)$ & $\left(\mathrm{ohm} / \mathrm{cm}^{2}\right)$ & & 70.38 \\
\hline $\mathrm{TiO}_{2}$-ref. & 1.89 & 360 & 1.83 & 22.79 \\
\hline $\mathrm{am} @ \mathrm{TiO}_{2}$ & 1.79 & 67.35 & 1.65 & 4.44 \\
\hline $\mathrm{IrO}$-am@TiO & 1.61 & 34.11 & 1.73 & \\
\hline
\end{tabular}




\section{References}

[S1] Kresse, G., Joubert, D. From ultrasoft pseudopotentials to the projector augmentedwave method. Phys. Rev. B: Condens. Matter Mater. Phys. 1999, 59, 1758-1775.

[S2] Kresse, G.; Furthmuller, J. Efficiency of ab-initio total energy calculations for metals and semiconductors using a plane-wave basis set. Comput. Mater. Sci. 1996, 6, 15-50.

[S3] Perdew, J. P.; Burke, K.; Ernzerhof, M. Generalized gradient approximation made simple. Phys. Rev. Lett. 1996, 77, 3865-3868.

[S4] Dudarev, S. L.; Botton, G. A.; Savrasov, S. Y.; Humphreys, C. J.; Sutton, A.

P. Electron-energy-loss spectra and the structural stability of nickel oxide: An LSDA+U study. Phys. Rev. B: Condens. Matter Mater. Phys. 1998, 57, 1505-1509.

[S5] Gao, G. Y.; Yao, K. L.; Liu, Z. L.; Zhang, J.; Li, X. L.; Zhang, J. Q.; Liu, N. Magnetism and electronic structure of $\mathrm{Cr}$-doped rutile $\mathrm{TiO}_{2}$ from first-principles calculations. J. Magn. Magn. Mater. 2007, 313, 210-213. 